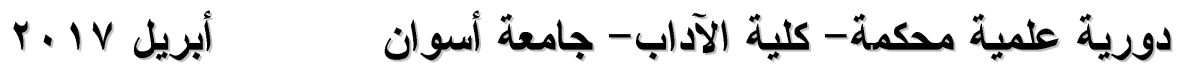

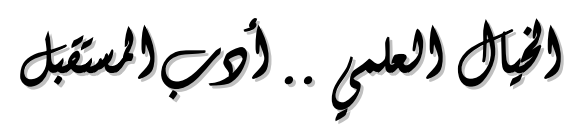

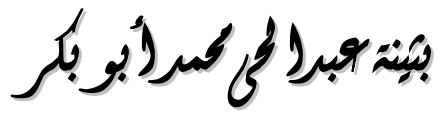

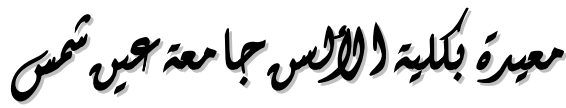

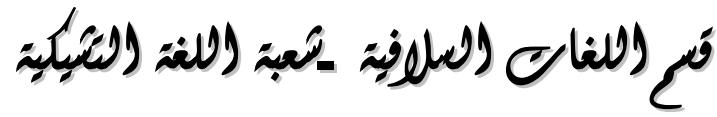




\section{الخيال العلمي .. أدب المستقبل}

في أعقاب الطفرة الصناعية في أواخر القرن الثامن عشر إلي منتصف القرن الثاسع عشر ظهرت تسمية عصر النهضة الصناعية، ثم سُمي النصف الأول من القرن القن

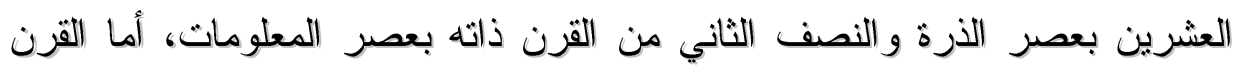

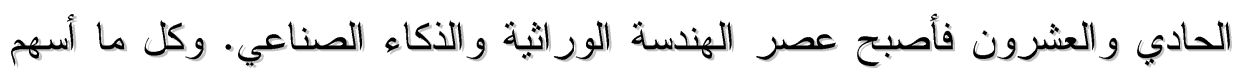

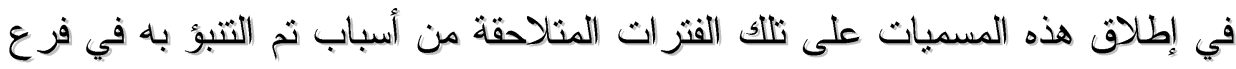

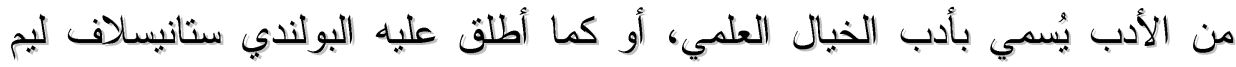
Stanislaw Lem

\section{تعريف أدب الخيال العلمي ونثأته}

يحبط بهذا النوع من الأدب، الذي رافق ظهوره كثير من الإهمال والسخرية

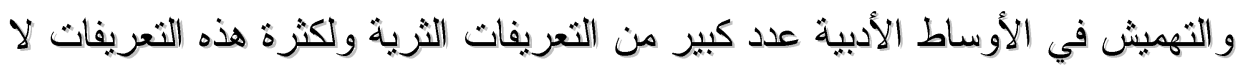

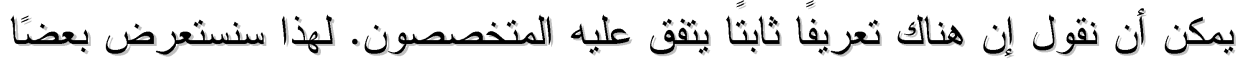
من هذه التعريفات لتوضيح ماهية أدب النوع.

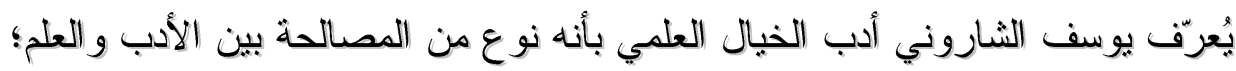

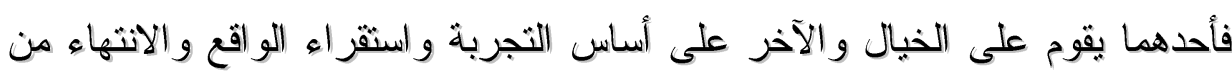

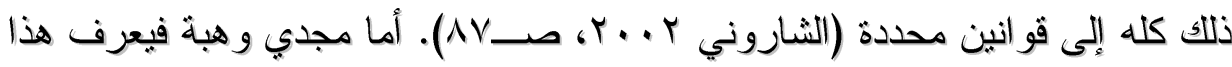
النوع من الأدب بقوله: "هو ذللك النوع من الأدب الروائي الذي يعالج بطريقة خيالية

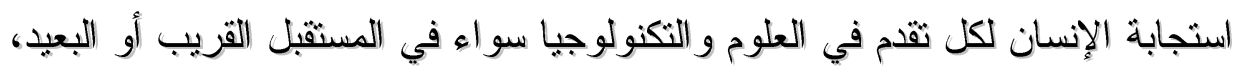

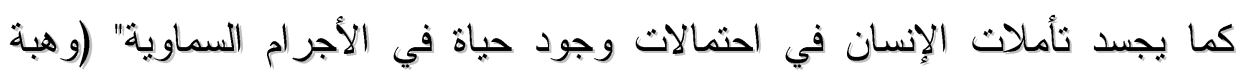

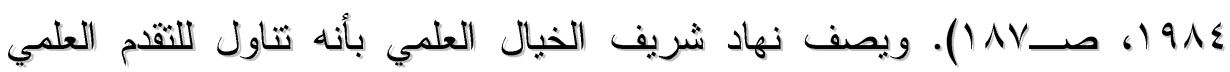
ومنجزات التقنية وتطور ها الصالح منها و الضار ، من خلال أحداث در امبة.

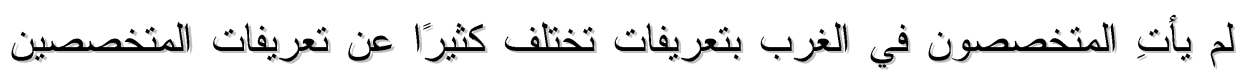
العرب. يقول الروائي الإنجليزي كينجسلي آميس بingsley Amis في كتاب له له 
بعنوان خرائط جديدة للجحيم (.97 (1): "إن القصة العلمية هي ذلك النوع من القصة

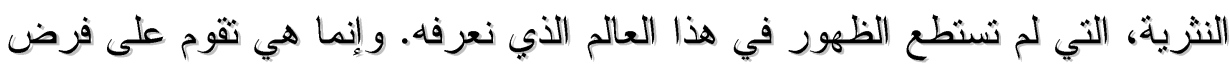

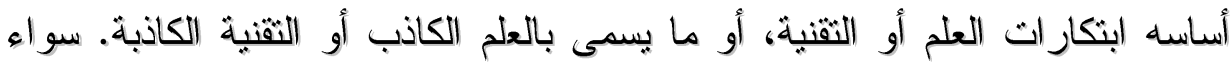

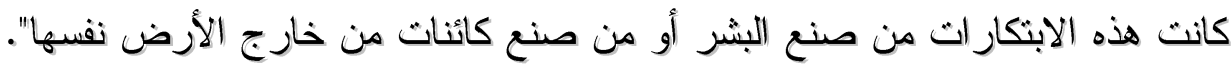

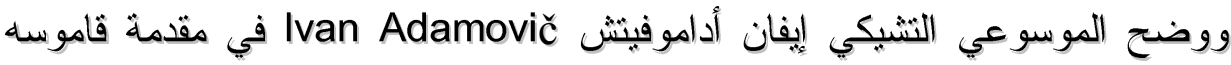

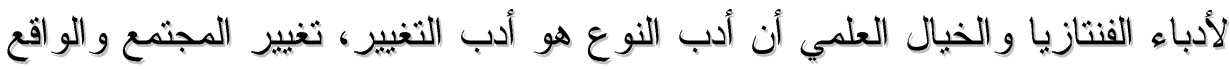
اليومي. هو ذلك النوع الأدبي الذي يهثم بنتائج ذلك التغيير، سواء كان التغيير عالميًا

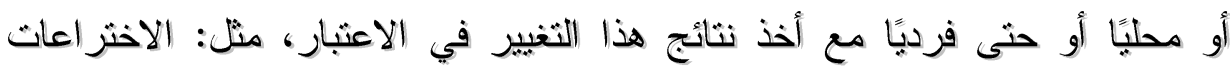

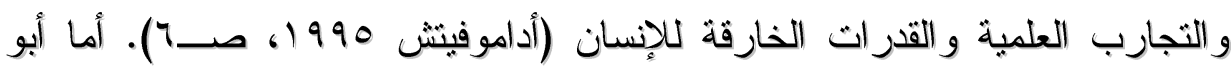
الخبال العلمي هوجو جرنسباك Hugo Gernsback فقد عرّف قصص النوع بأنها

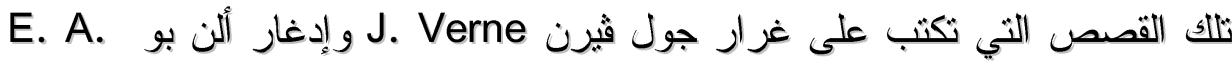
P. G. Wells وهربرت جورج ويلز Poe واختلف المتخصصون حول بداية هذا النوع من الأدب؛ رغم ارثباط أدب الخبال العلمي بالثورة الصناعية في نهاية القرن الثامن عشر وبداية القرن الثاسع عشر، يؤكد

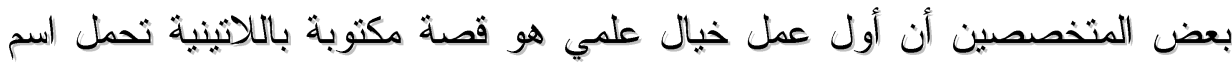

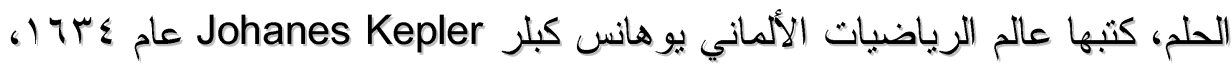

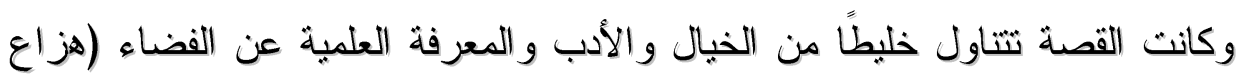

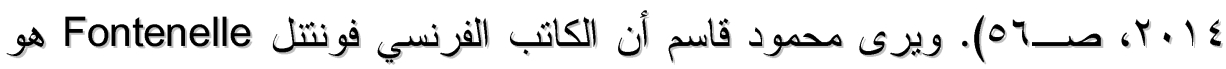

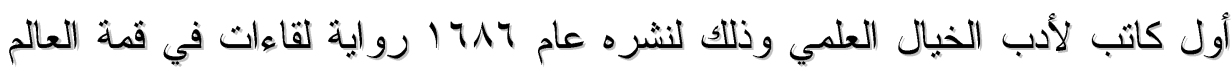

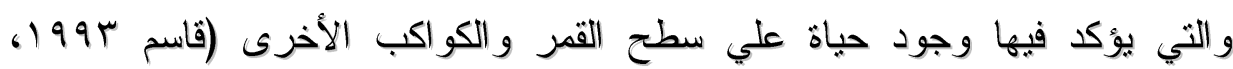
صـr (1). وهناك متخصصون آخرون بربطون أدب الذوع بظهور رواية الإنجليزية

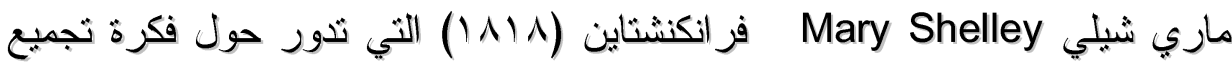
أعضاء بشرية وخلق إنسان منها أو بالأحري خلق مسخ بشري ذي مصير بائس يشبه

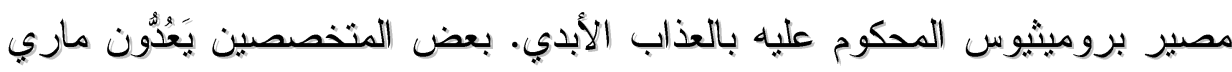

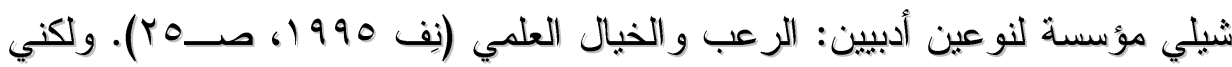
في حقيقة الأمرككثير من المتخصصين أفضل أن أرجع البداية الحقيقية لأدب الخيال

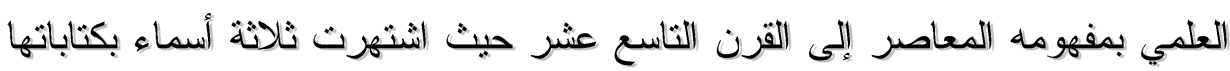




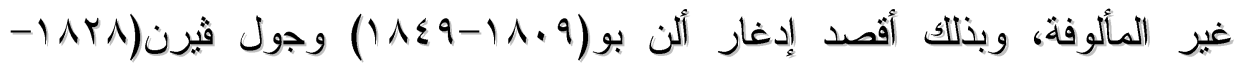

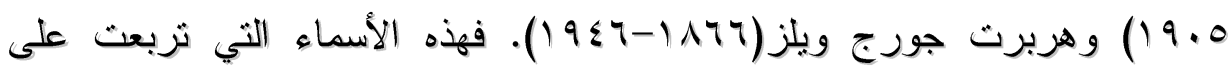

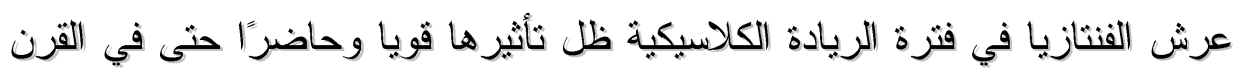

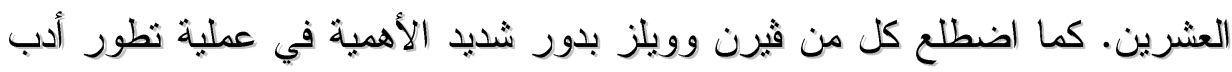

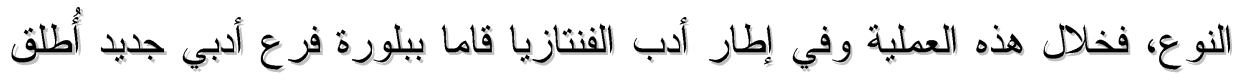
عليه لاحقا الخبال العلمي.

ترجح غالبية الدر اسات أن ميلاد مصطلح أدب الخبال العلمي Science fiction كان

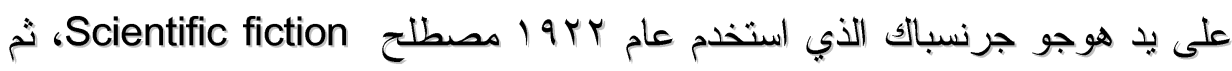

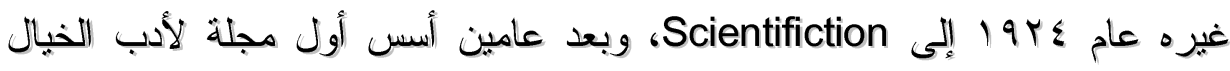

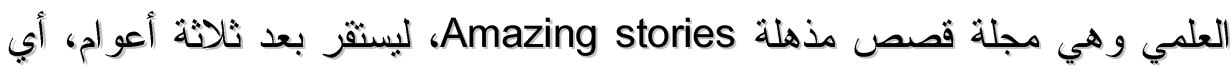

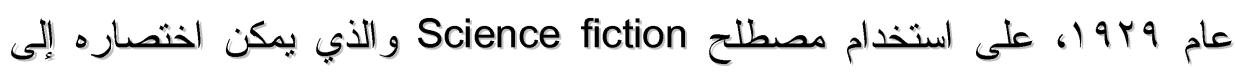

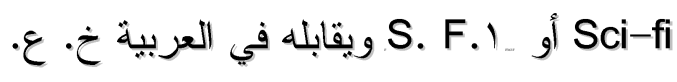

وقلة من الباحثين مثل بر اين سثيلفورد Brian Stableford يرجعون أصل التسمية

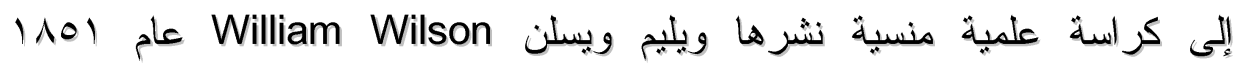

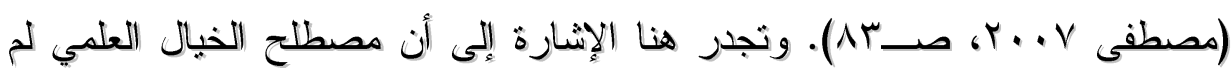

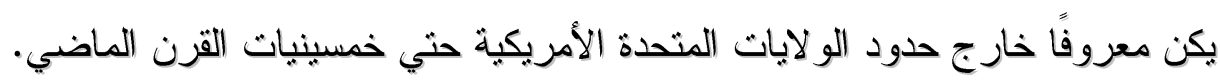

\section{الفانتازيا والخيال العلمي واليوتوبيا}

' توضح ليزا توتلي في كتابها فن كتابة الفنتازيا والخيال العلمي أن الكثير من الكتّاب والمهتمين بالخيال العلمي

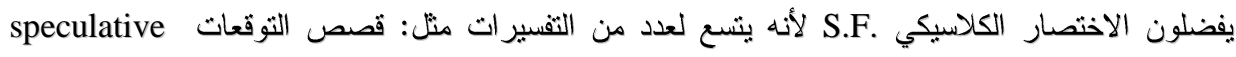

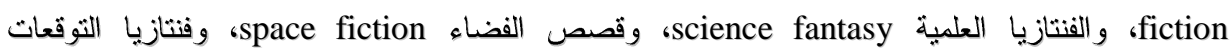
.speculative fantasy 
وقبل أن ننتقل إلى وظائف أدب الخيال العلمي وتصنيفاته ينبغي لنا أن نوضح الفرق بين مفهوم الفانتازيا و الخيال العلمي و اليوثوبيا؛ فالأنو اع الثلاثة تلثقي في بعض ون النقاط وتفترق عند البعض الآخر. هناك ميل عام في سوق الكتب إلى الجمع بين الفنتازيا

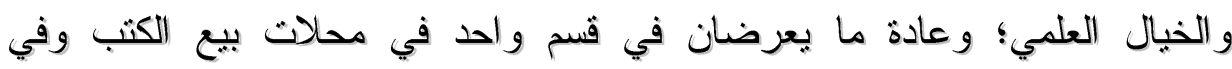
المكتبات.

منذ القدم والإنسان في حاجة لتفسير ما يدور في حباته اليومية من ظواهر طبيعية

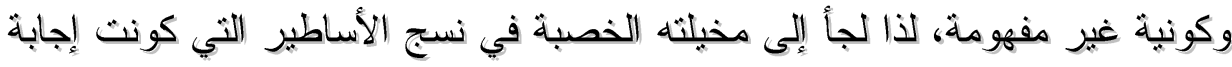

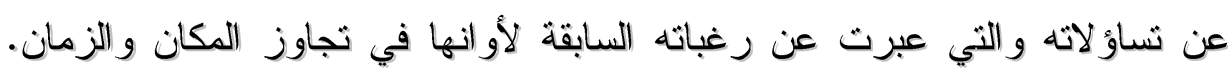
وشكلت هذه الأساطير البداية لأدب الفنتازيا الذي يعده البعض الخياته الخيال العلمي للإنسان

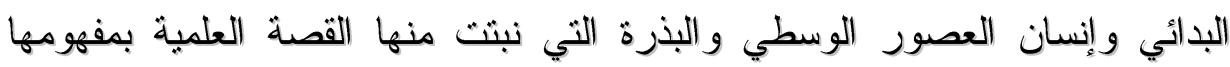

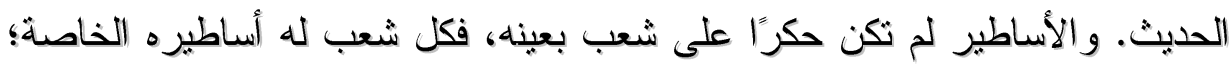

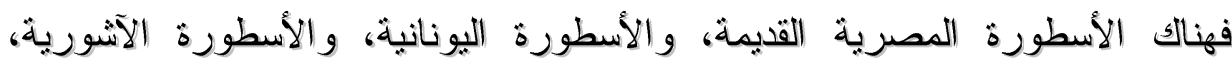
والأسطورة الصينية ... إلخ. ظهر أثر هذه الأساطير في بعض الأهورة الأعمال مثل ملحمة

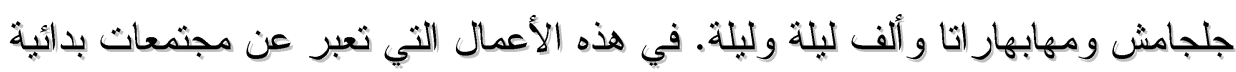

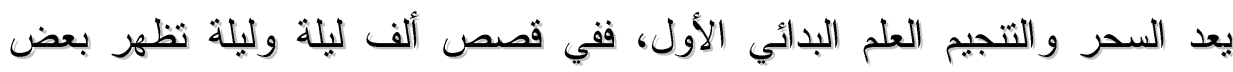

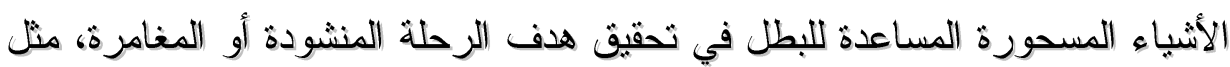

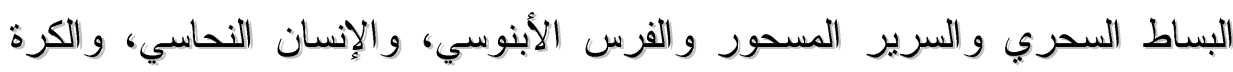

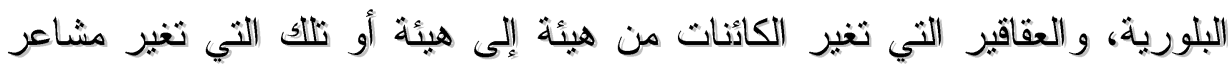
شخص ما تجاه شخص آخر، واستبدل كاثب الخيال العلمي بكل هذه هئه الأشياء مخترعات حديثة كالطائرة والصاروخ ومركبة الفضاء والإنسان الآلي و التلفزيون و التركيبات الكيميائية المختلفة.

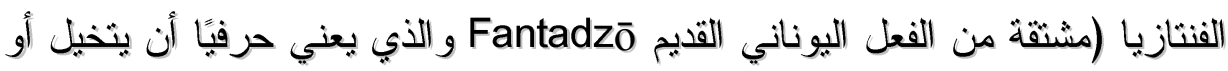

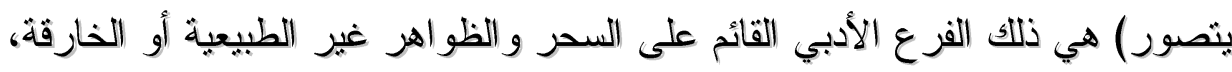
هي ذلك الأدب الذي يعبر عن رغبة الإنسان في تجاوز حدود الزمان و المكان دون

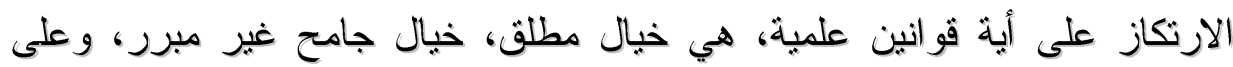

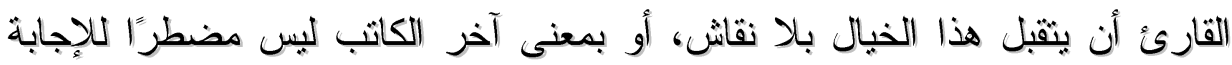

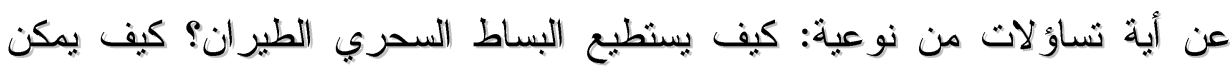


لأحدهم حبس عفريت أو جني في قمقم؟ ما هي مكونات هذا الترياق الذي حول الأمير إلى ضفدع؟ لماذا تستخدم الساحرات مكنسة في الطير ان؟ وهذه فئ الفكرة يؤكدها رابي

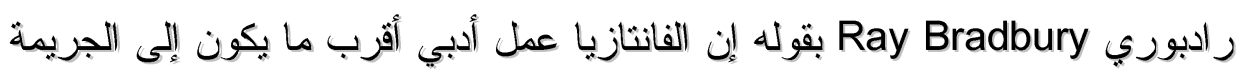
الأدبية؛ فبإمكان الفانتازيا أن تهاجم القوانين الطبيعية الثابتة وتتخطاهيا.

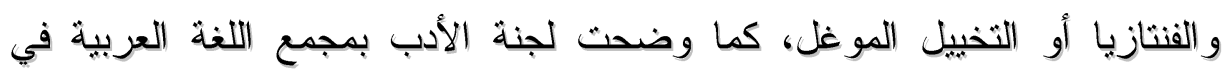

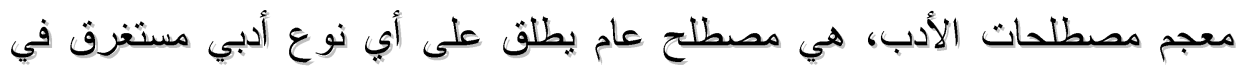

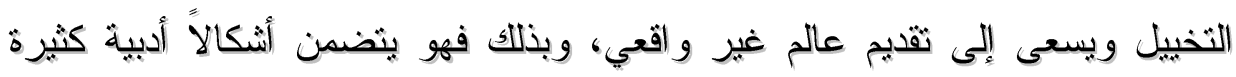

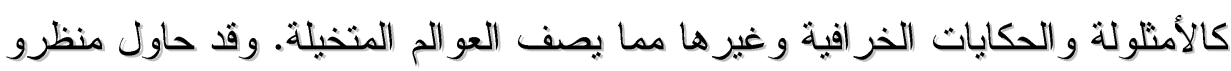

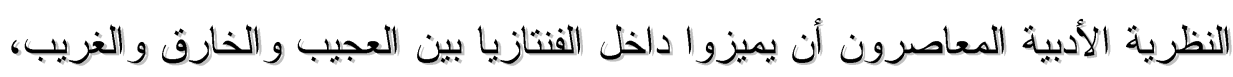

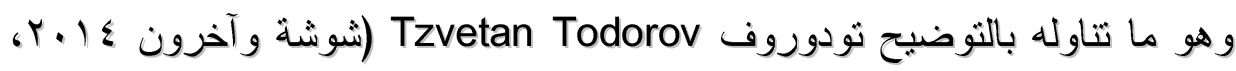

. صـ و

يُعرِّف يوزفِ بيتركا Josef Peterka الفانتازيا بأنها "أدب غير و اقعي قائم على

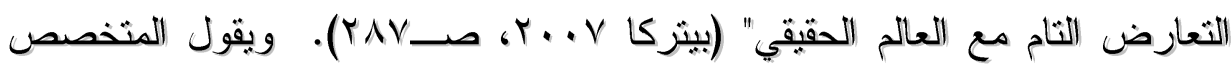

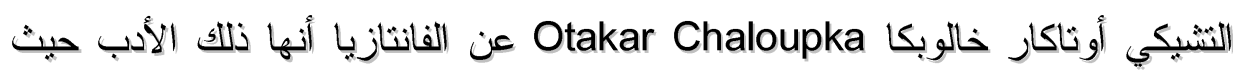
كل شيء ممكن: حيث نكون أسلحة الليزر في مو اجهة السيوف، و الفرسان في مو اجهة

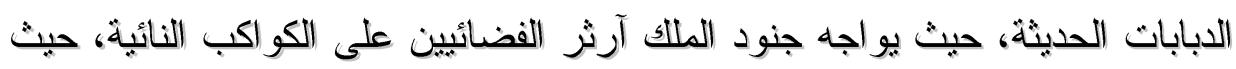

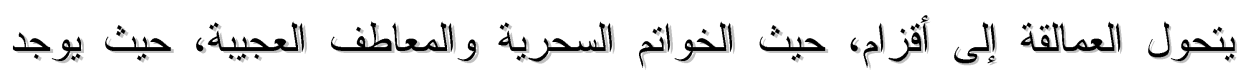

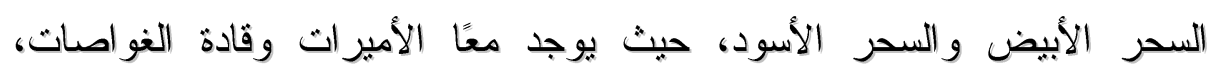

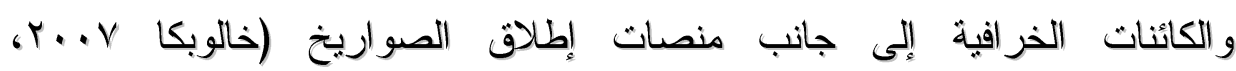

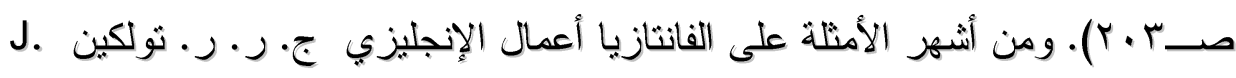
(الهوبيث (19 R. R. Tolkien

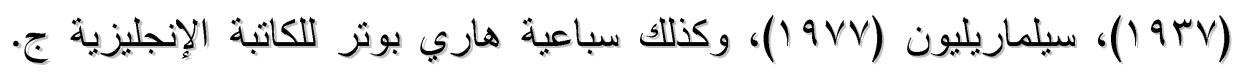

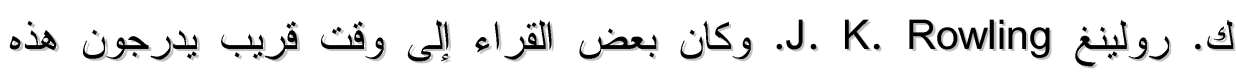

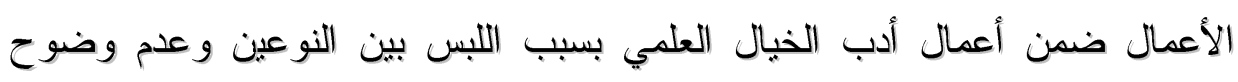
الحدود الفاصلة بينهما. وفي الأدب التشيكي ظهرث الفنتازيا في أعمال عديد من بن ونين

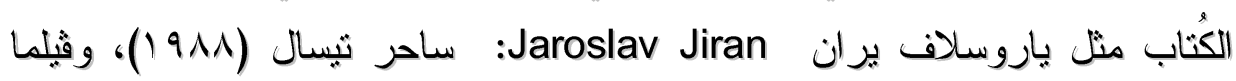

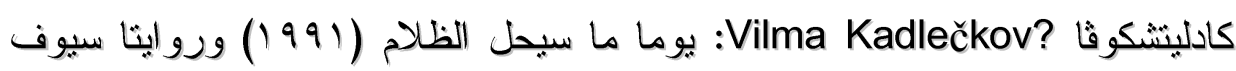




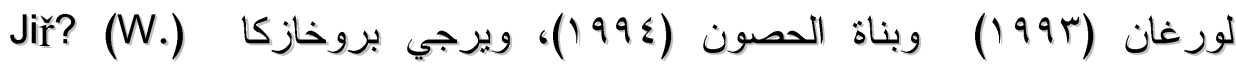
Sroch?zka

ومن هنا يمكننا أن نستنتج أن الفانتازيا خبال قائم على السحر و الخوارق، أما الخبال

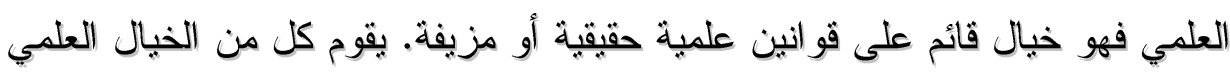

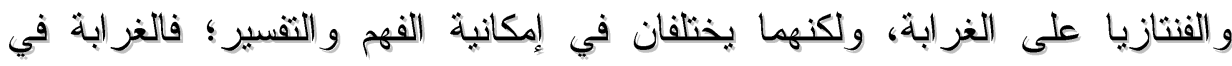
الخيال العلمي غرابة منطقية وبها معقولية افتر اضية، لكن الغرابة في الفنتازيا خارقة

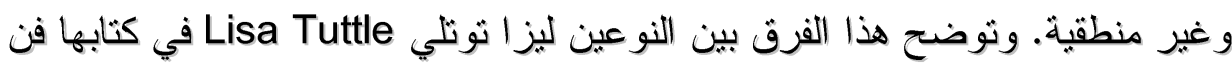

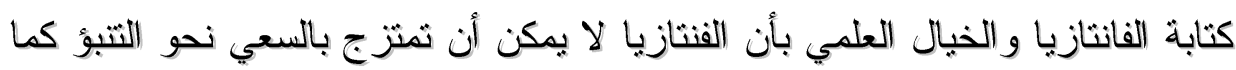

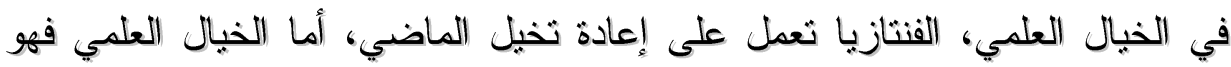

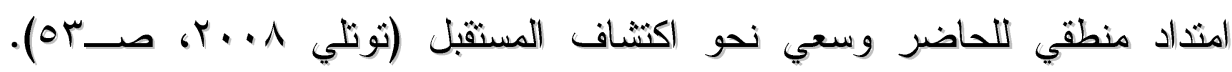

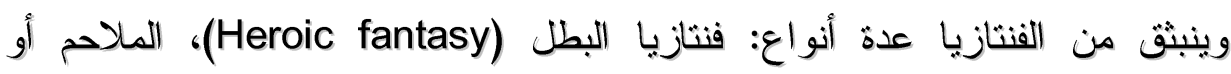
الفنتازيا الر اقية (Eric or high fantasy)، فنتازيا الحكام (Dynastic fantasies)،

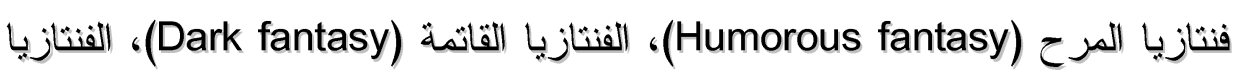
الرومانسية (Romantic fantasy) و غير ها.

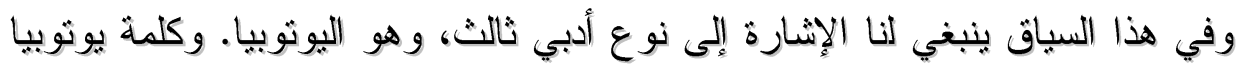
Utopia

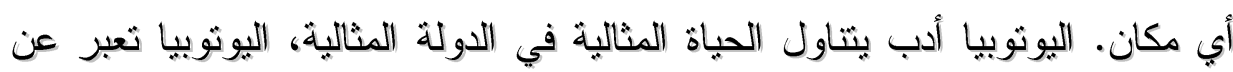

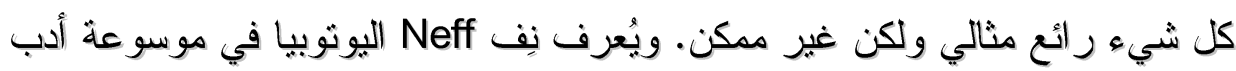

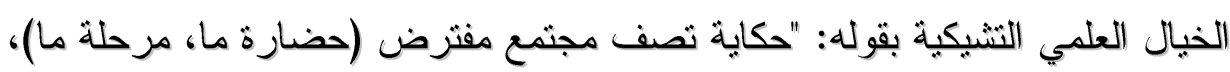

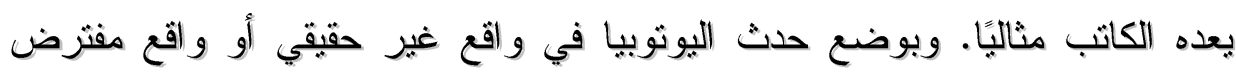

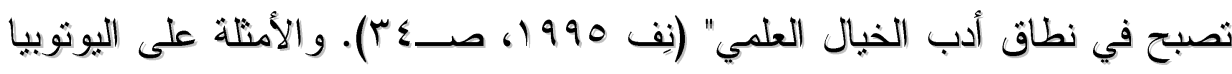

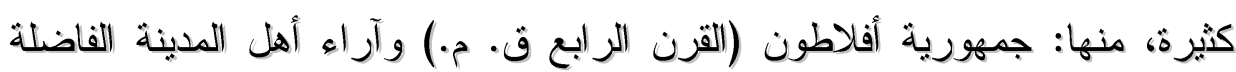

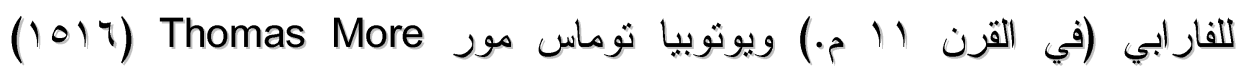
و أطلانتس الجديدة لفرانسيس بيكون Francis Bacon (דب آ1) ومثاهة العالم وجنة 


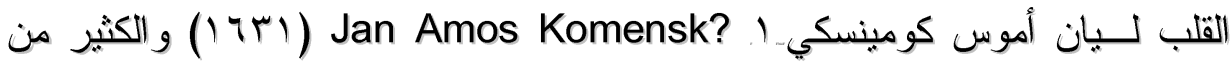
الأعمال من مختلف الآداب. ويمكننا أن ندرج بعض اليوثوبيات مثل يوتوبيا مور

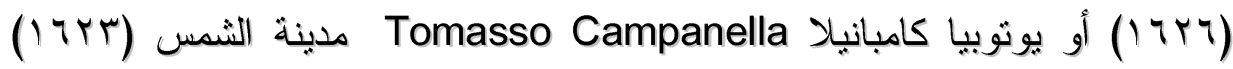
ضمن يوتوبيات الخيال العلمي؛ حيث إنها تقدم عالما مبهرًا من الناحية العلمية و التكنولوجية.

وتقسم الدكتورة عزة الغنام اليوتوبيا نوعين، النوع الأول يستقبد من الثقدم العلمي

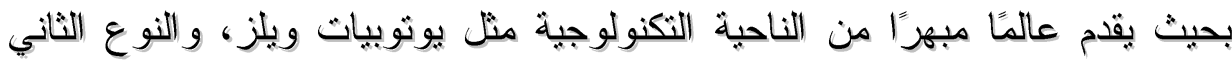
يصور الإنسان في أحسن صورة ويعثمد المجتمع في هذا النوع على أن الإنسان

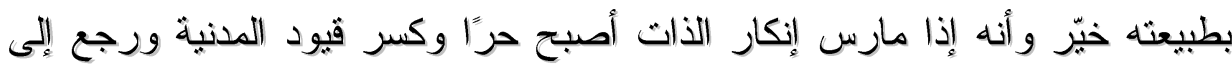

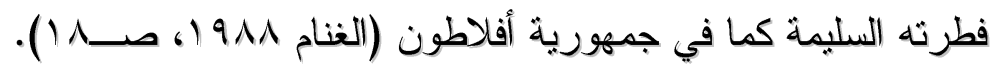
و العمل الذي يقدم عالمًا كابوسيًا بما فيه من تكنولوجيا حبث أصبح التقدم العلمي مأساة تطيح بالقيم الأخلاقية والإنسانية، يمكننا أن نسمبه المدينة الفاسدة أو دستوبيا Dystopia زامياتين Jamjatin ورواية ألدوس هكسلي Aldous Huxley عالم جديد شجاع

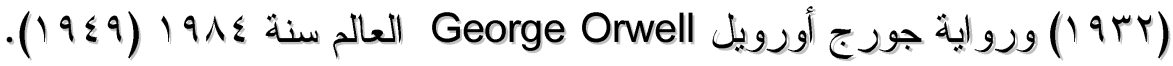
ففي دولة هكسلي في رواية عالم جديد شجاع يعلو شعار "الجماعة- التشابه-

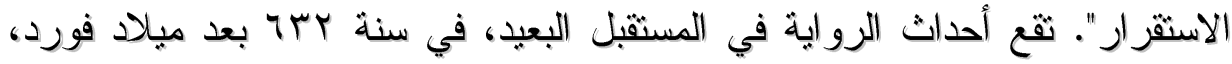
وهو تقويم ابتدعه الكاتب. يثحكم في عالم الرواية عشرة أشخاص، ثم يليهم إداريو معامل التفريخ و التكييف المركزية. و الثعب يُصنف إلى ألى أربع طبقات: الألفا والبيتا

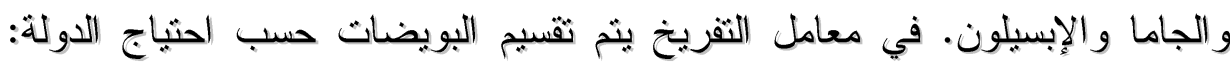

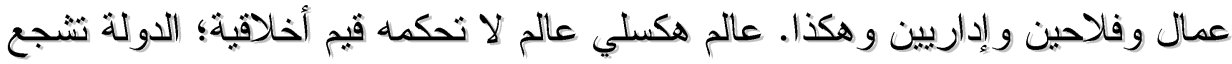

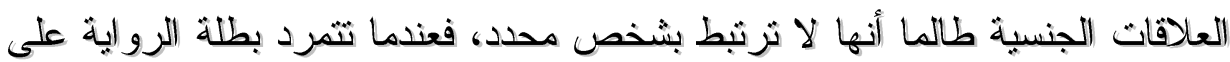

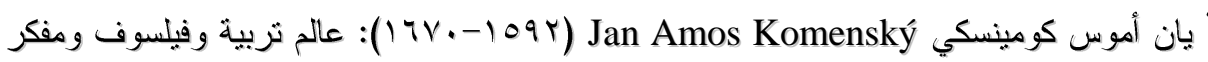

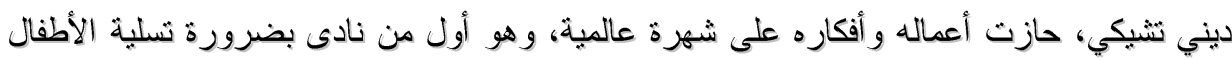

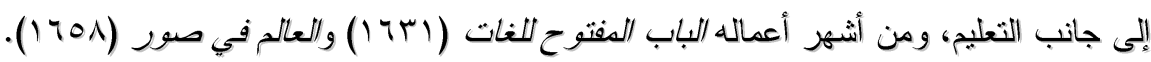


هذا العرف ثتحدث معها زمبلثها بأن في ما ثفعله مخالفة لمبدأ: "الكل للواحد و الو احد للكل".

\section{أنواع الخيال العلمي ووظائفه}

يقسم النقاد الخيال العلمي نوعين: الخيال العلمي الجاف أو الخشن أو المنضبط Hard، و الخيال العلمي الناعم Soft. يثميز الخيال العلمي الجاف بالاهنمام بالثفاصيل العلمية،

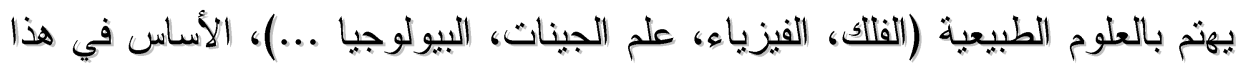
النوع الناحية العلمية والتكنولوجية، مثال على هذا النوع عمل للكاتب الأمريكي هال

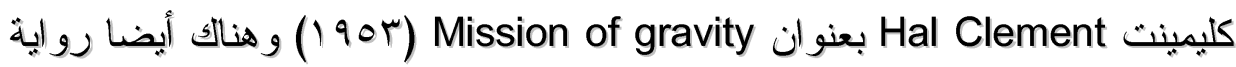
لخبير علوم الفضاء التشيكي كارِل باتسنِر Karel Pacner بعنو ان رحلة إلى المريخ

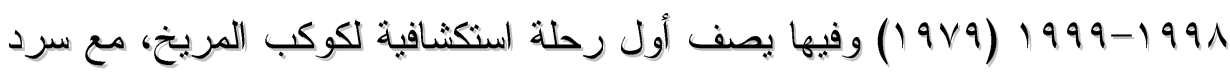
الكثير من الحقائق العلمية المصحوبة بالصور و الخرائط وحساب المخطط الزمني

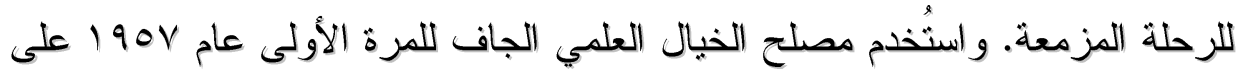
يد P. Schuyler Miller وذلك لوصف بعض قصص النوع في العصر الذهبي للخيال العلمي (نِف 19901، صـ9 وب-.ب). أما الخيال العلمي الناعم فيثميز بالعناية بالموضو عات الاجتماعية و النفسية و الفلسفية و السياسية، مثل أعمال راي بر ادبوري.

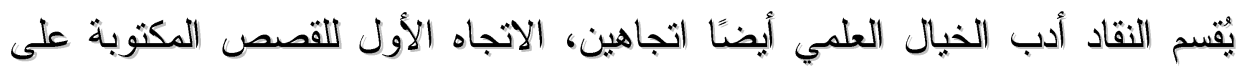
غرار جول ثيرن الذي كان شديد الحرص على ثناول النواحي العلمية في قصصيه، وبذلك يكون ثيرن مؤسس الاتجاه التكنولوجي المعني بعالم الإنسان الخارجي.

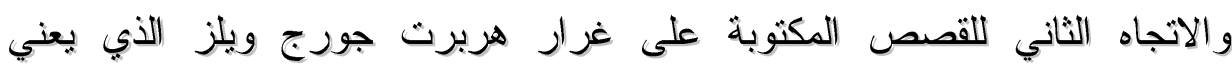
بمشكلات المجتمع و الأفكار الفلسفية، وبذلك يكون ويلز مؤسس الاتجاه الفلسفي المعني

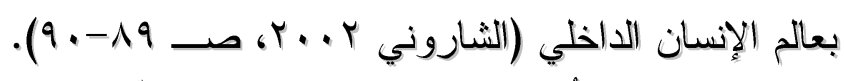

يُقسم النقاد أيضا كُتاب الخيال العلمي فريقين: كتّاب مجربين، وكتّاب متخصصين أو أو مخلصين. و الكتّاب المجربون هم الذين يقومون بثقديم عمل أو اثثين أو ثلاثة أعمال

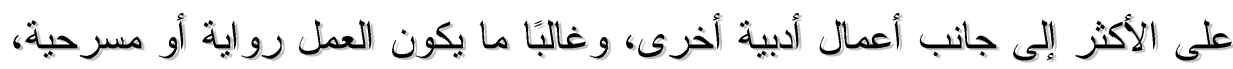


مثل توفيق الحكيم من مصر وكارل نشابيك Karel Čapek من التشيك. أما المتخصصون فهم مخلصون لأدب النوع و لا يكثبون غيره، ويكثبون القصة القصيرة

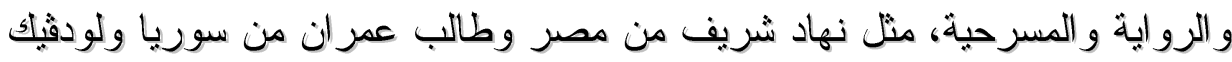

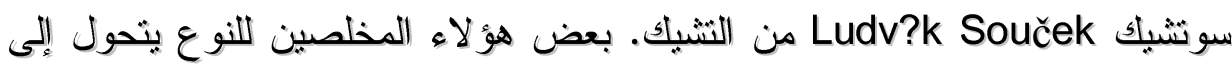

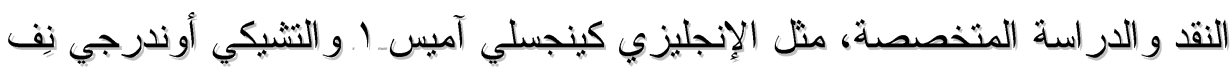

\section{.Ondřej Neff. $r$}

وفيما يتعلق بالثكل الأدبي الذي يُقدم فيه الخيال العلمي، يمكنا القول إن أدب النوع

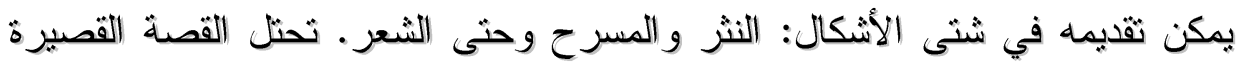

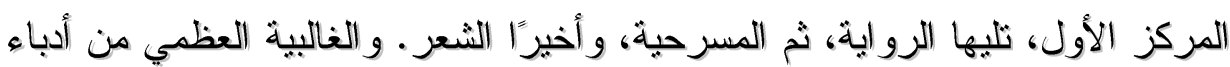

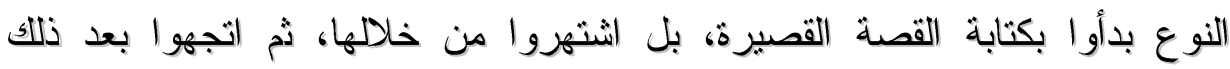

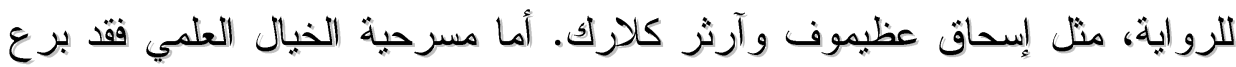
فيها من الكتاب العالميين الأمريكي راي برادبوري و البولندي ستانيسلاف ليج، وفي

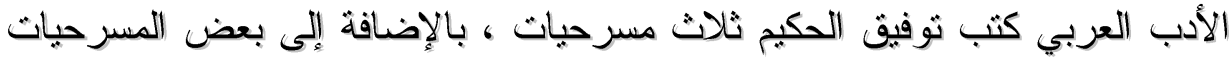

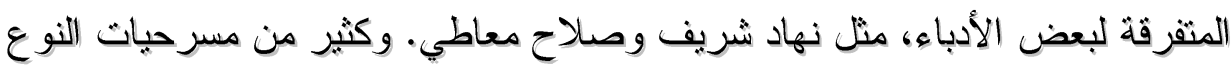
مأخوذة في الواقع من أعمال روائية أو قصصية.

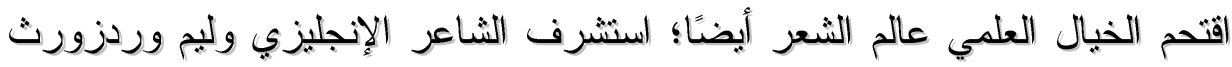
(1 10.-1VV•) William Wordsworth

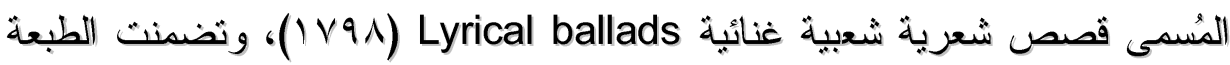
الثانية عام . .11 قصائد جديدة ومقدمة إضافية. هنالك أيضًا قصبيدة خيال علمي

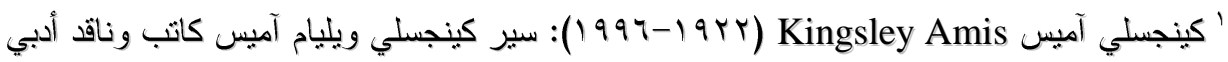

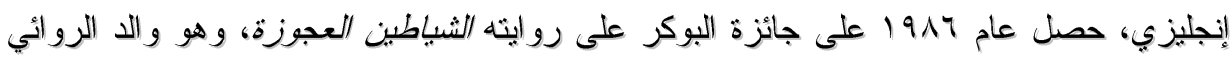
المعاصر مارنن آميس.

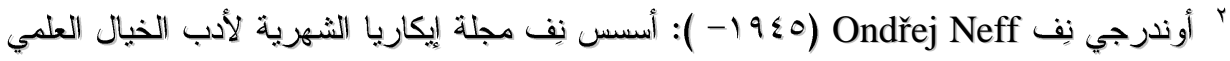

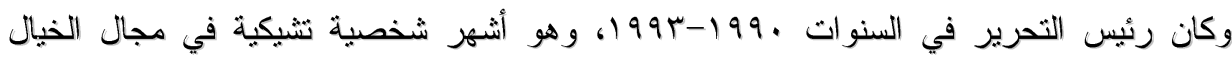

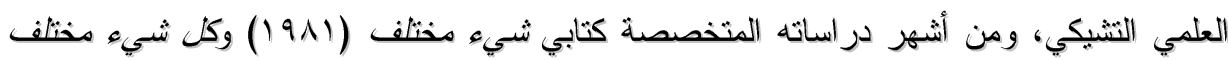

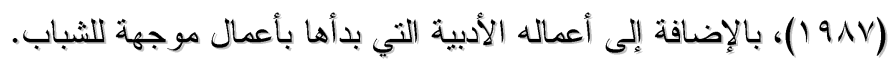


للشاعر الفيتنامي ثرانج خانه شانه بعنوان مناظر طبيعية مصغرة، نذكر منها الأبيات الثالية: - مالية

مثل الجسيم بمجاله الكمي، ومجاله المغناطبسي، ومجال جاذبيته تكون الصورة المصغرة للذرة، ومثل الذرة تكون الصورة المصغرة للكون.

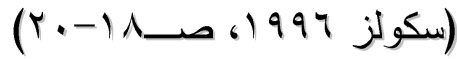

للخيال العلمي ثلاث وظائف جوهرية: وظيفة دعائية، ووظيفة تحذيرية نقدية، ووظيفة

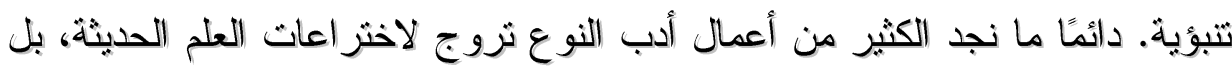

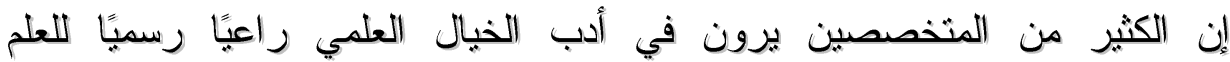
و الثكنولوجيا و المواهب العلمية. وفي هذا الصدد نشر إسحاق عظيموف دراسة بعد بردي الاحتفال بصدور كتابه المائثين، وكتب فيها: مائة من الشباب يقرأون أون الخيال العلمي، خمسون منهم سوف يتجهون إلى دراسة العلوم بشغف، وخمسة وعشرون سوف يعملون في مجال العلوم، واثنا عشر سوف يتخصصون في مجال العلوم بقية حياتهم،

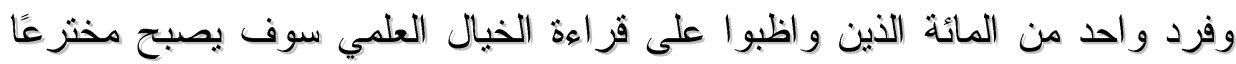

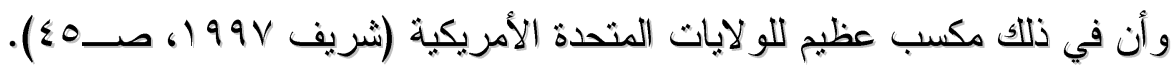

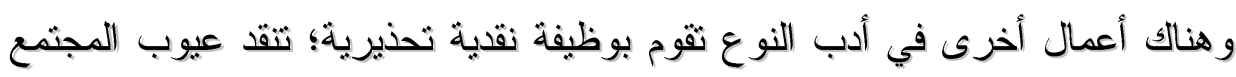

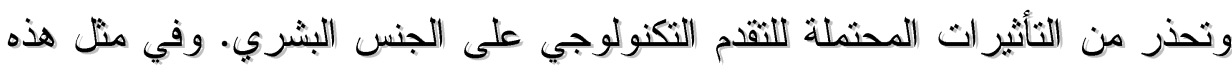

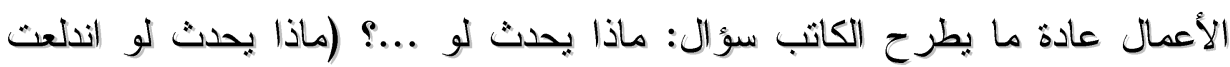

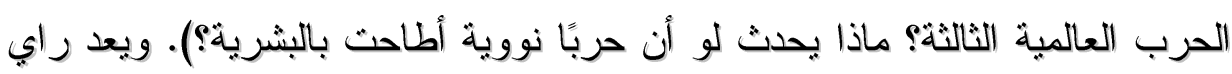

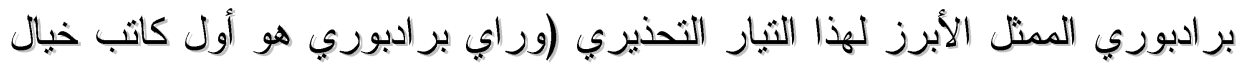

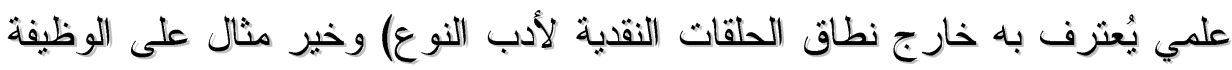

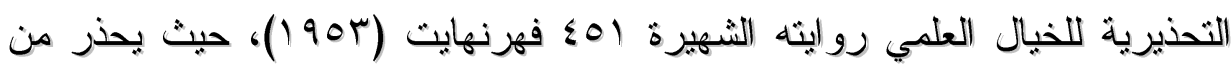
خطر النكنولوجيا المتشعبة في كل جوانب الحياة ومن أسلوب الحياة الأمريكي. ورو ايثه هذه ثعكس مأساة المثقين الأمريكيين في الخمسينيات و المعاناة من الإرهاب

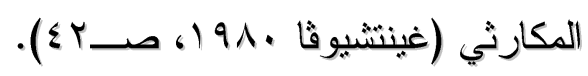


ومجموعة أخرى من قصص الخبال العلمي تقوم بالتنبؤ بالمستقبل واستشر افه. مثل

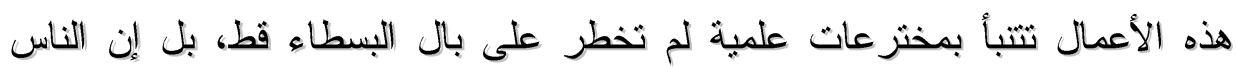

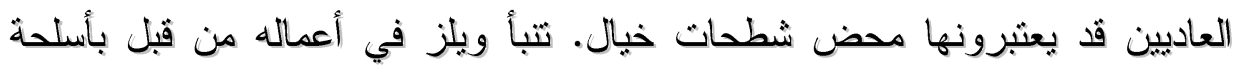

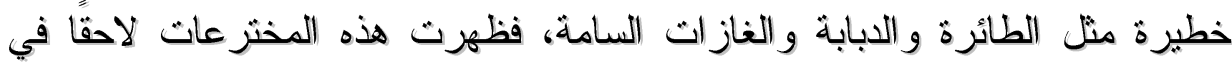

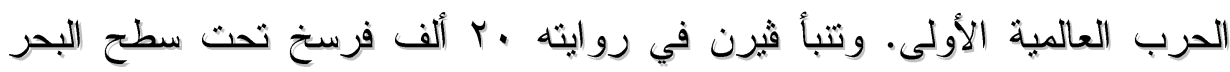

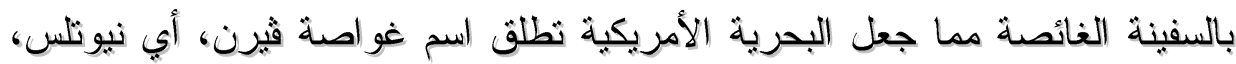

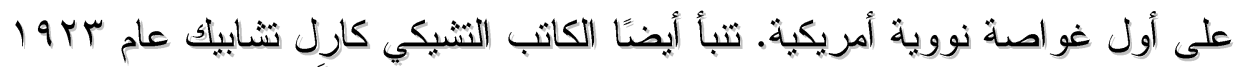

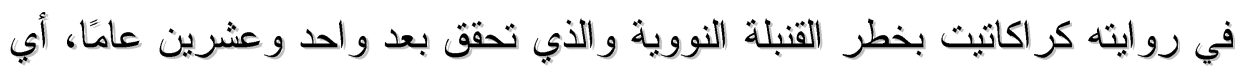
في الحرب العالمية الثانية. وتعقيًا على الانفجار النووي في هيروشيما وناجاز اكي لهي

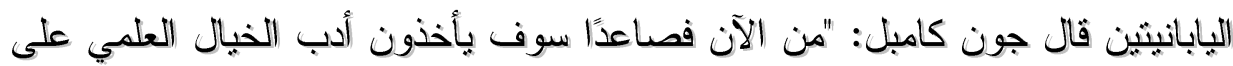
محمل الجد". و لا يمكننا هنا أن نغفل عما ردده البعض فئ في شأن ثمويل وكالة الفضاء

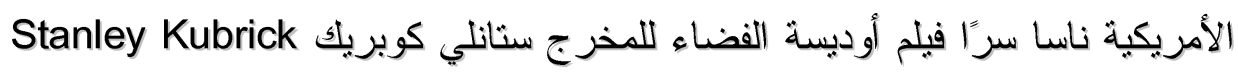

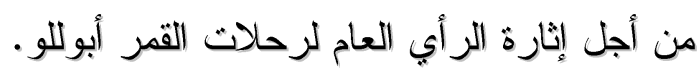

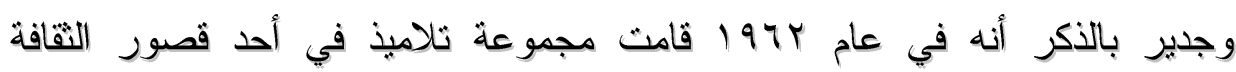
بموسكو ببحث ممتع؛ حيث قام الأطفال بثجيل كل المخترعات والأفكار التكنولوجية التي وردث في قصص جول ثيرن وبمساعدة أحد المتخصصين ثم الثأكد من عدد الأن الأفكار التي صارث حقيقة على أرض الواقع، وكانت النتيجة إيجابية: ثم تحقيق أربع

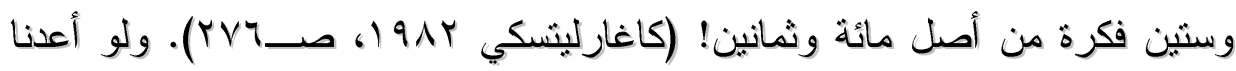
هذه التجربة في الوقت الراهن لأصبح عدد الاختراعات أكبر من أربعة وستين. إذًا

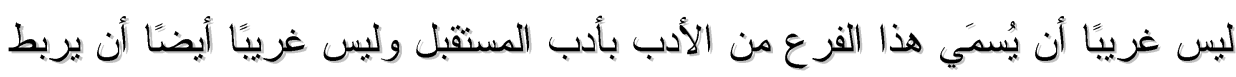
بعض النقاد جودة بعض الأعمال بمدى صدق ثتبؤ الكاثب بالمستقبل.

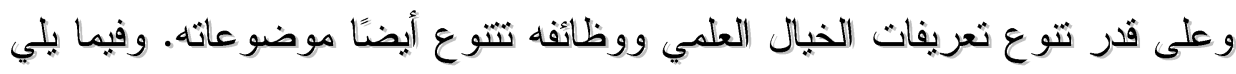

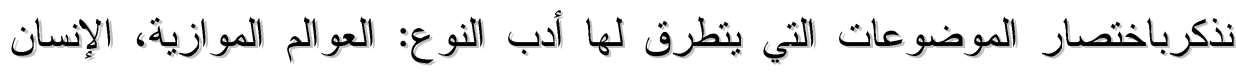
الآلي (الروبوت)، الأندرويد (، الأنثروبوجيا، أطلانتس، الفضاء ورحلاتهاته، استعمار

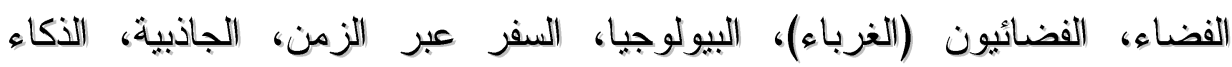


الاصطناعي، الوعي الجمعي، المتحولون (المنطورون جينيًا)، الجنس، الخلود،

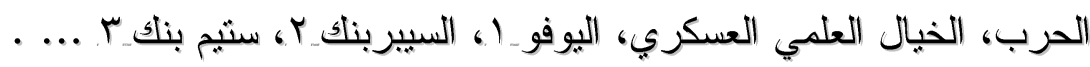

\section{العصر الأهبي للخيال العلمي}

عندما نقول العصر الذهبي للخبال العلمي، فنحن نعني هنا الخيال العلمي الأمريكي.

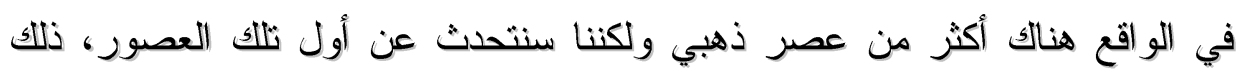

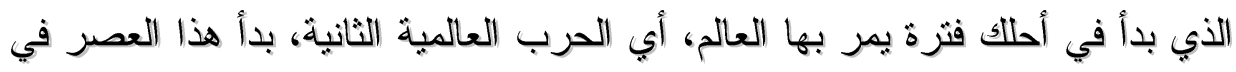

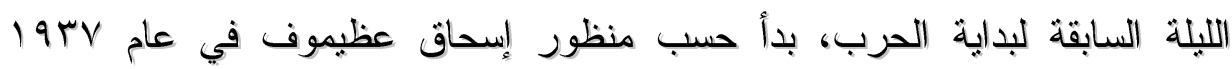
و انتهي عام •190، ذلك لأن هذه الفترة ارثبطت بارثناع مكانة المحررين وظهور

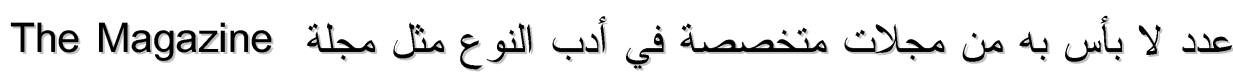
.of Fantasy and S.F.

يرثبط هذا العصر باسم واحد دون غيره وإن كثرت الأسماء حينها، يرثبط باسم

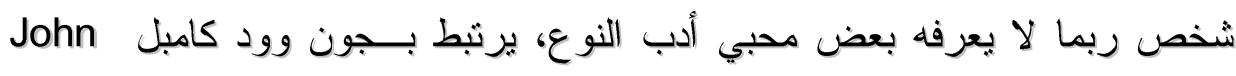
Wood Campbell ج. إدواردز M. J. Edwards إنه أسهم أكثر من أبي شخص آخر في تشكيل أدب الإنسي الخيال العلمي الأمريكي.

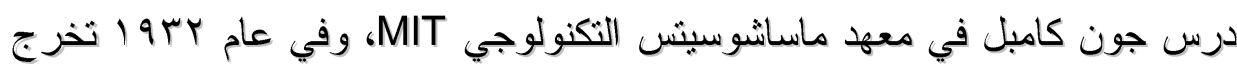

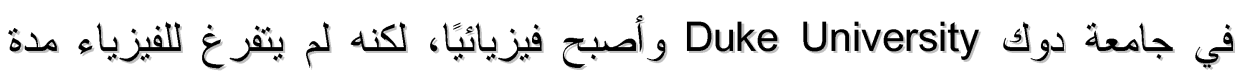

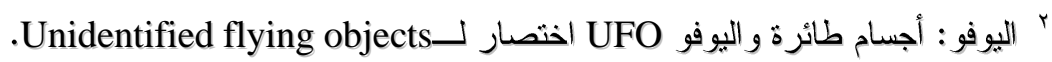

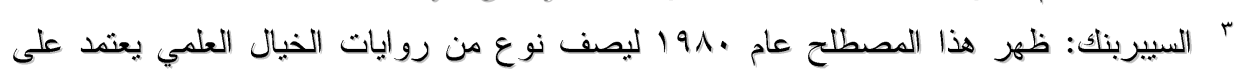

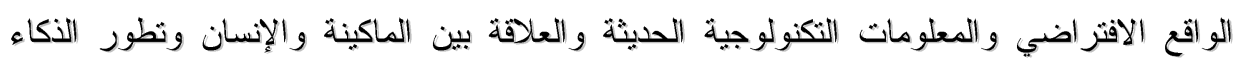

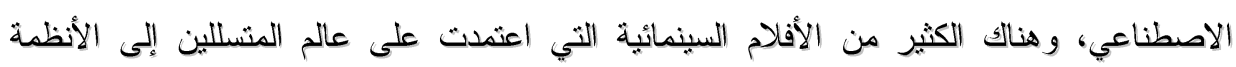
الحاسو بية مثل فيلم ماتريكس The matrix.

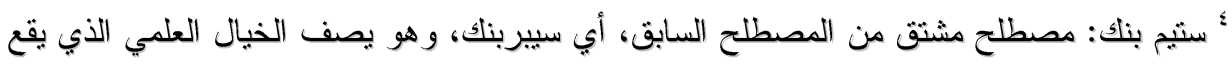

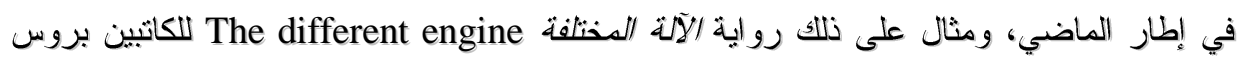

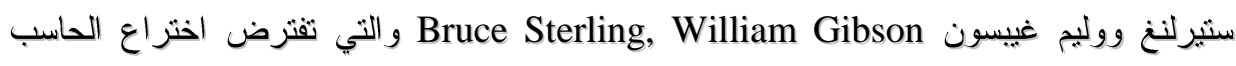
الآلي قبل العصر القيكتوري. 
طويلة؛ فقد كان منذ الصغر مولعًا بقصص ثيرن المنشورة في المجلات التي يحررها

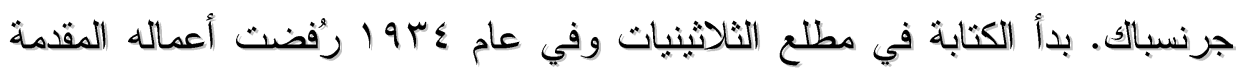

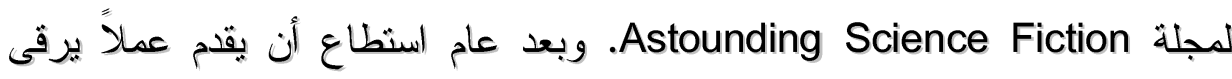

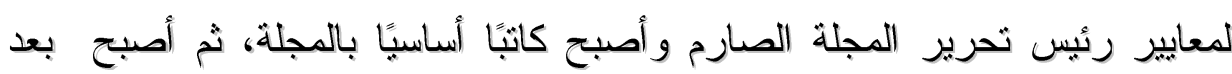

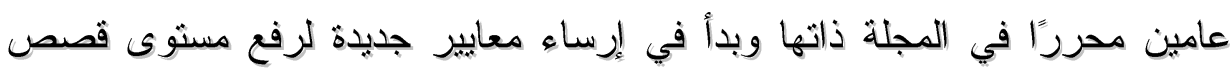
النوع.

كان كامبل يؤكد على ضرورة أن نكون الأفكار المقدمة في القصص مثيرة ومنطقية، ومن هنا يأني دوره العظيم حيث دأب على إيجاد كثّاب مميزين، كان لهم الفضل فئل لاحقًا

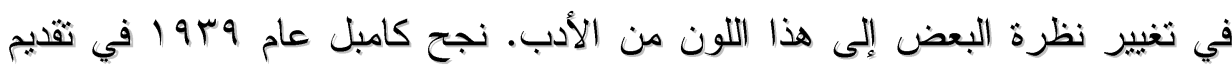

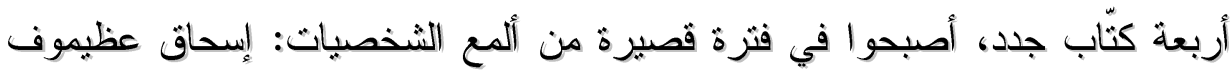
Robert Anson Issac Asimov

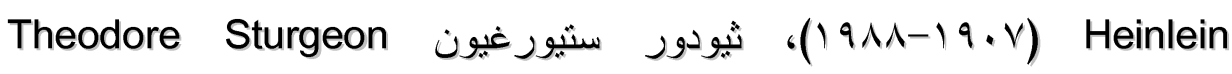

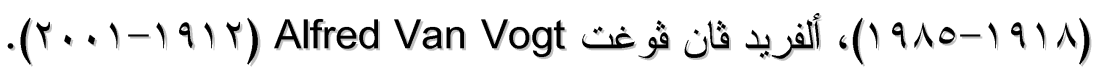

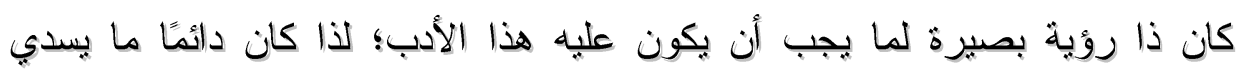

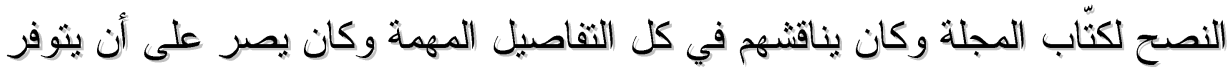

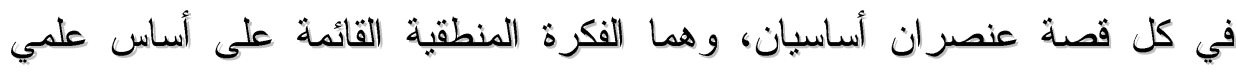

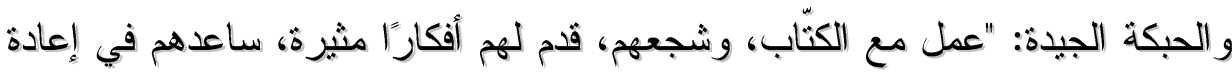

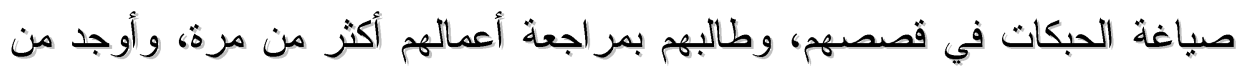
خلال المحادثات الثخصية و الرسائل المطولة، والافتتاحيات المنبهة، مناخًا للإثارة

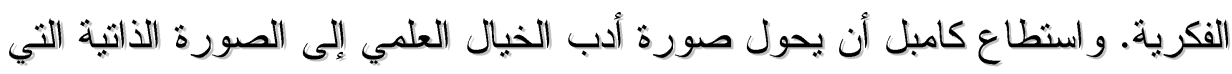

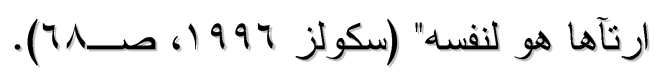

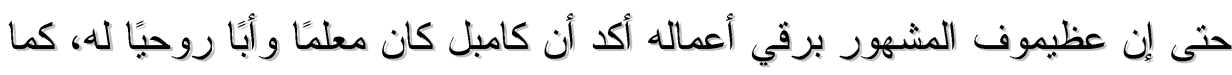

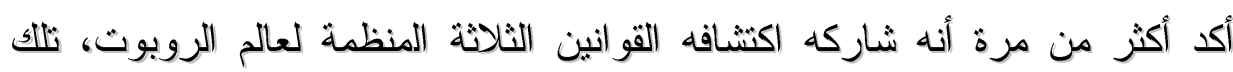

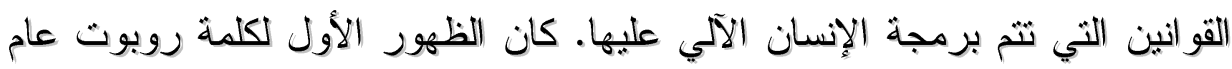

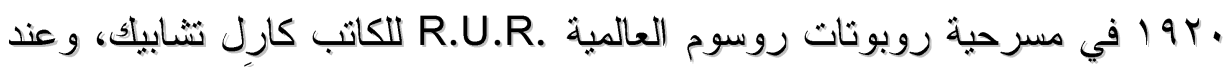

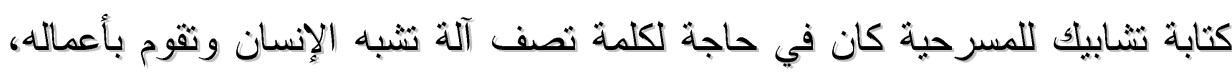

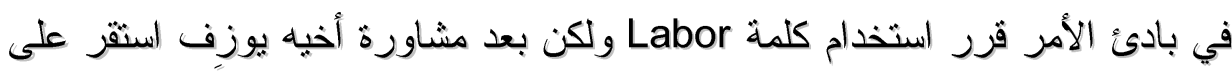


استخدام ما اقترحه أخيه، أبي كلمة Robot، وهي في الأصل مشتقة من الفعل التشبكي القديم Robotovat و الذي يعني العمل دون مقابل أو العمل بالسخرة، أو من كلمة الته Robota القصة القصيرة الكاذب (1) (1) (العلى الآتي: على الروبوت ألا يؤذي الإنسان أو حنى أن يثسبب بتكاسله في أي أذى لهاته.

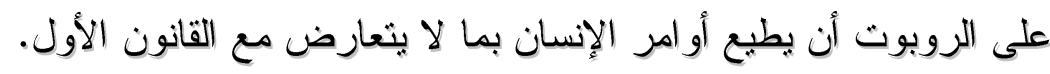

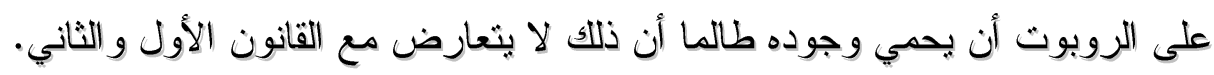

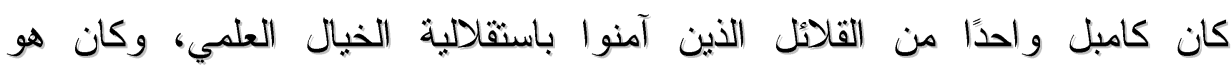

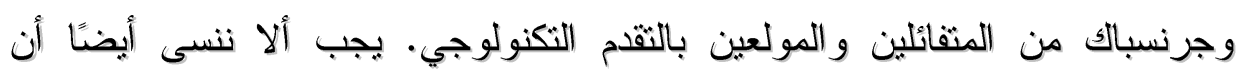

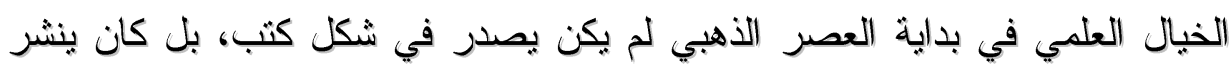

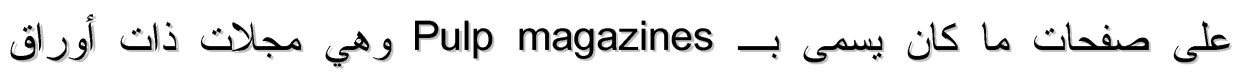
صفر اء رديئة يخجل حاملها من ظهور غلافها الفج أمام الآخرين، وقد يقوم بإِخالها

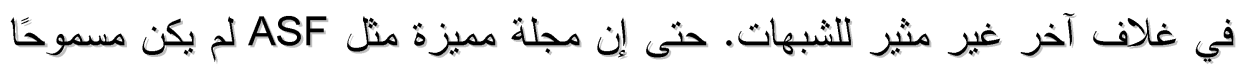

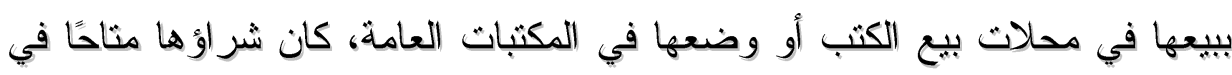

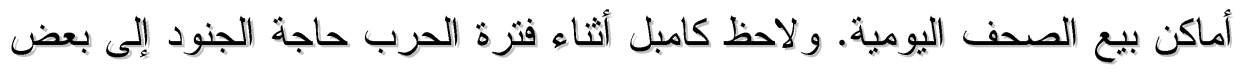

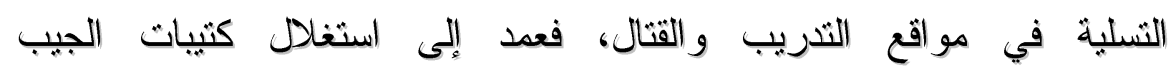
التي كان الجنود يتهافتون على شرائها، فكلف عددًا من أفضل كثابه

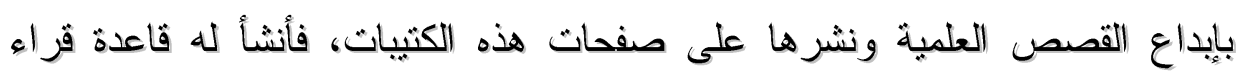

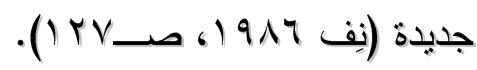

\section{التكنولوجيا ومصير البشرية}

من أهم أهداف الخيال العلمي الارنقاء بالحضارة البشرية والوصول إلى درجة أعلى البه

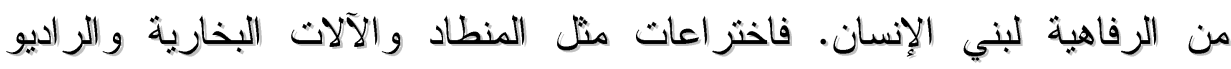

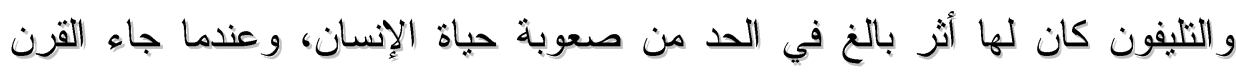
العشرين زاد تطور هذه الآلات وظهرث الطائرة والتلفزيون، ثم الصارون و الكمبيوثر والطاقة النووية. ولكن تبقى بعض الأسئلة مطروحة وبحاجة إلى الثأمل: 
هل زادت هذه الأجهزة من سعادة الإنسان وراحته ورفاهيثه؟ هل كل شيء يصنعه

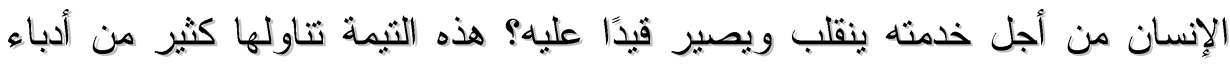

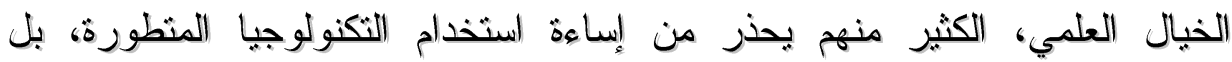
أصبحت هذه الثيمة شائعة في قصص النوع بعد اندلاع الحرب العالمية الثانية. في إطار هذا الموضوع يمكننا نقسيم أدب الخيال العلمي فرعين: أدب الخيال العلمي

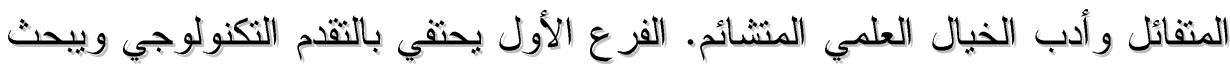

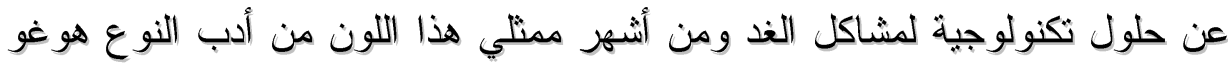

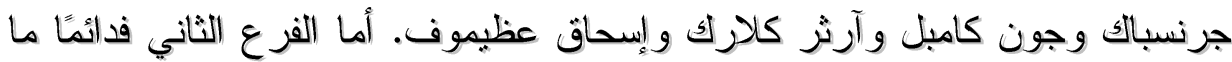
يشير إلى الآثار السلبية الناجمة عن الثطور التكنولوجي المتصاعد بشدة. ويحذر ممثلو

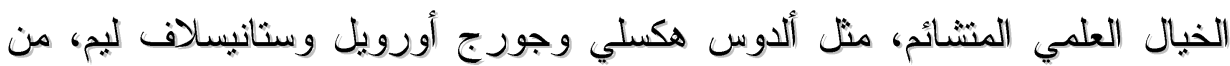
المستقبل البائس الذي قد يكون نتيجة حثمية لتخلي العلماء عن أخلاقيات البحث

وكتّب الخيال العلمي المثشائم يتناولون في قصصهم المشكلات المستقبلية المحثلة،

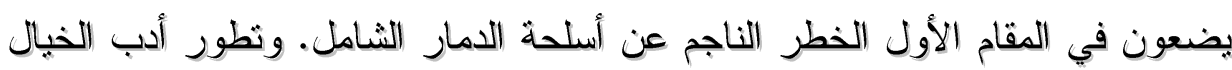
العلمي الأمريكي و السوفيتي مرثبط بالحرب العالمبة الثانية حيث ثمت إساءة استخدام الطاقة النووية: "الو لايات المتحدة قد هاجمت مدينتين يابانيثين بالقنابل الذرية، المدينة

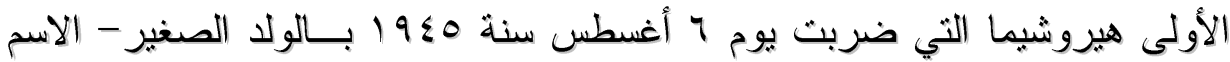
الكودي للقنبلة، و المدينة الثانية ناجازاكي التي ضربت بـديث بـالرجل السمين- الاسم

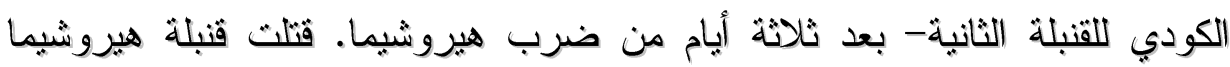

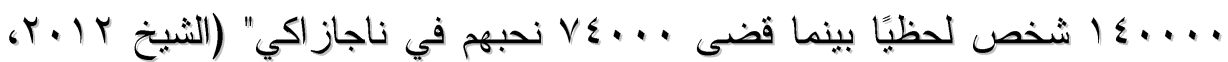
صــ1). وفي المقام الثاني نجد التهديد الذي يشكله التغيير المناخي ونتائجه. هذا الموتيف مصدر إلهام لكثير من الأدباء. ومن الكوارث التي قد يسبيها التغيير المناخي

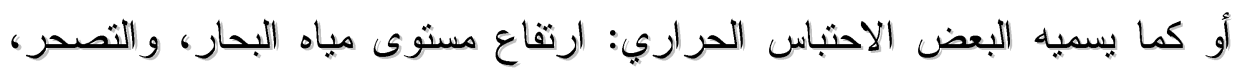

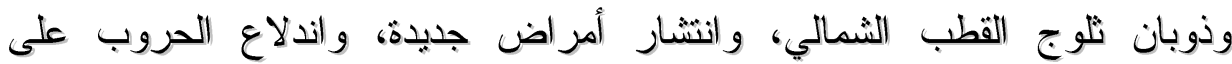

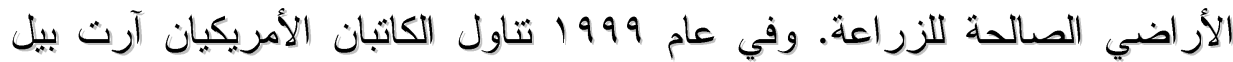
Art Bell من التغيرات المناخية في رواية بعنوان اقتراب العاصفة الكبرى ( The coming 
global superstorm )، تحذر الرواية من النتائج المحتلمة للاحتباس الحراري، فعدم

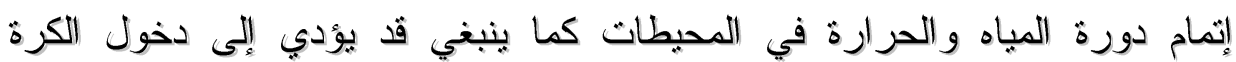
الأرضية في فترة جديدة من الفترات الجليدية.

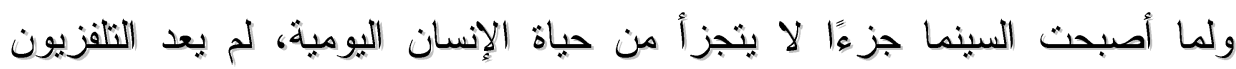

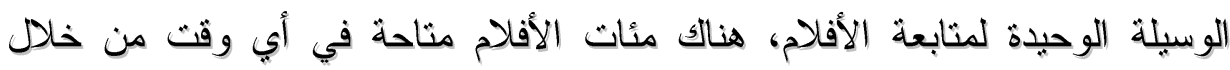

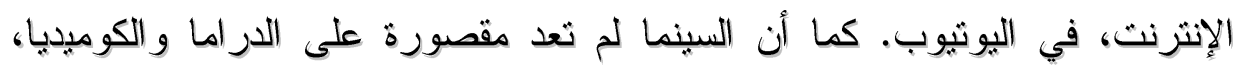
اخترقت السينما ألوانا أخرى مثل الفنتازيا والخيال العلمي. ومنذ البداية سينما الخيال

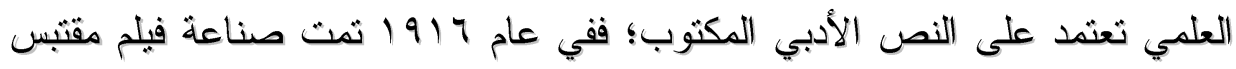

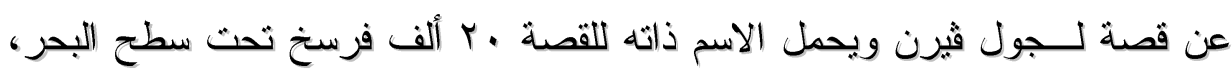

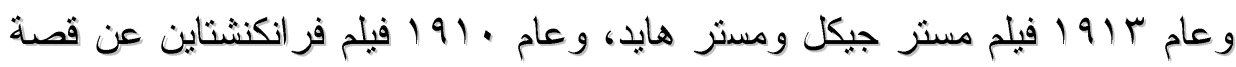
ماري شيلي. بمكنا القول إن السينما لها فضل كبير في أن يثعرف عامة الناس ولو من بعيد على العى عالم العلماء والبحث العلمي، بل إن لها إسهامًا خاصًا في ارتفاع شعبية أدب الخيال العلمي، وهذه الشعبية ازدادث منذ النسعينيات وحنى الآن بفضل نطور النكنولوجيا

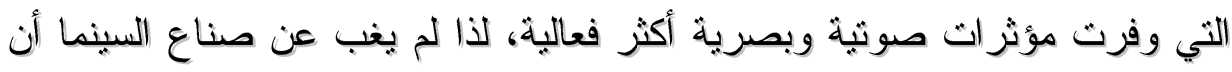

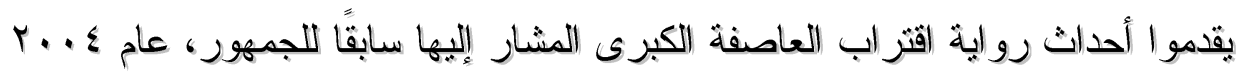
عرضت دور السينما الأمريكية فيلم The day after tomorrow وكان من إخراجه إبهابه

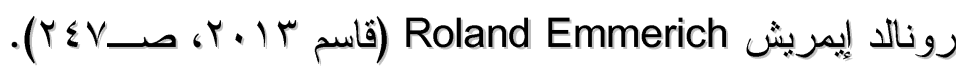
ويحل في المرثبة الثالثة للموضوعات المفضلة عند كتّاب الخيال العلمي المتشائم

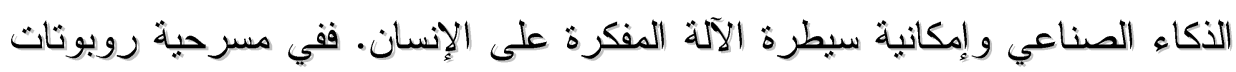

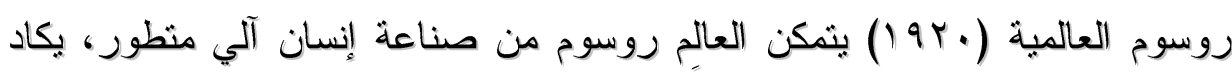
يشبه البشر إلى حد كبير، فيحل هذا الإنسان الآلي محل العمالة البشرية، ويثم

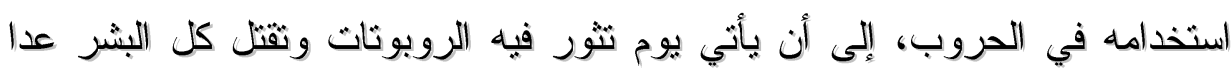

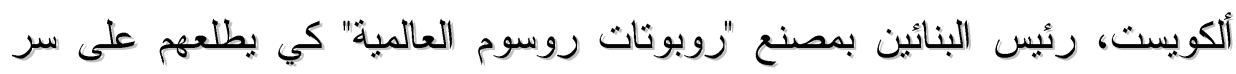

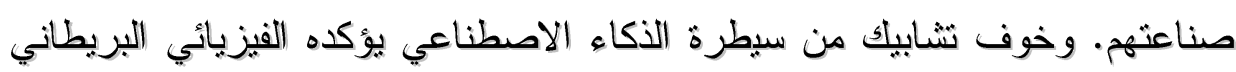

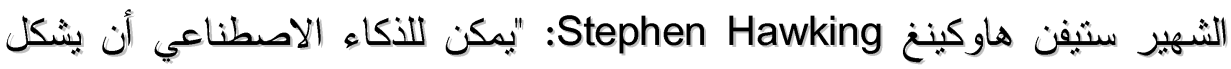


عالمًا مستقلاً بذاته، ويمكنه أن بطور نفسه بسرعة باستمر ار ـ و الإنسان بطبيعة تطوره

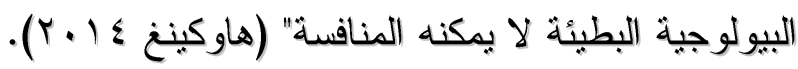

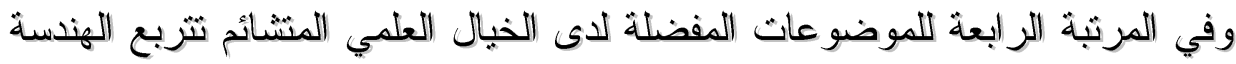

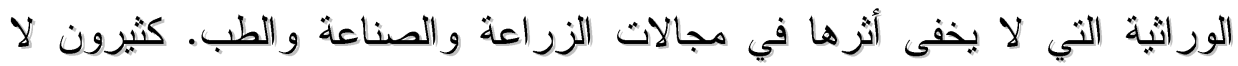

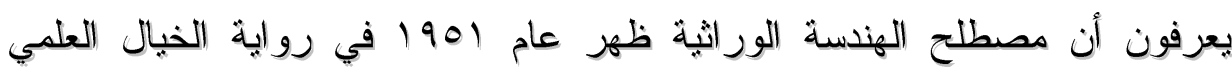

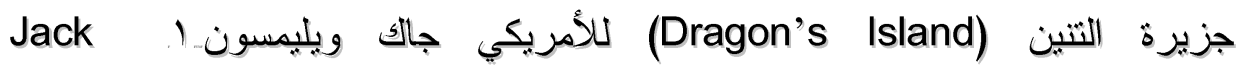
Williamson

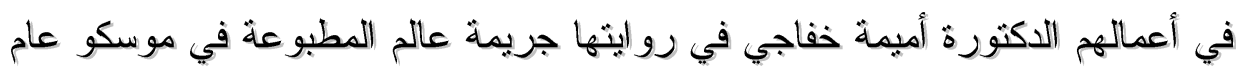

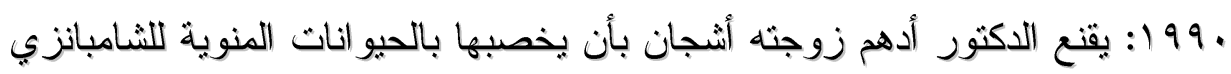
سنوسي، فتكون نتيجة هذا التخصيب طفلة شاذة ذات وجه جميل يشبه وجه أشجان

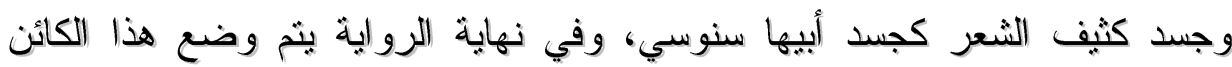

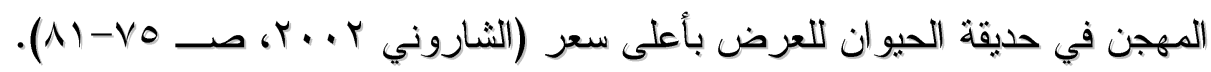

أدب الخيال العلمي العربي سُجلت الريادة في الخيال العلمي لإنجلتز اوفرنسا على يد مبدعيها ماري شيلي وجول

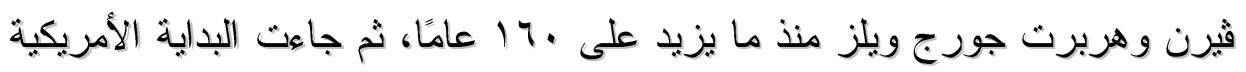

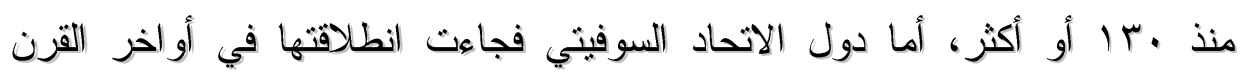
الثاسع عشر، و أخير البداية العربية منذ ما يزيد على الستين عامًا.

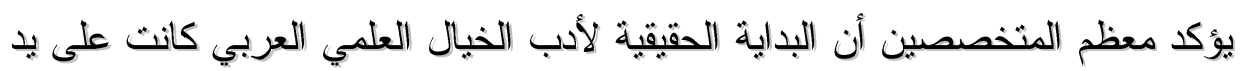

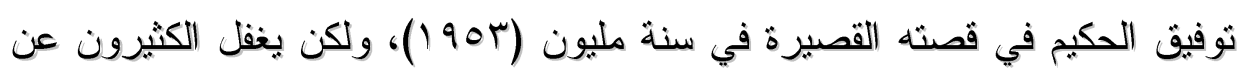
يوتوبيا الخيال العلمي في القصة القصيرة خيمي الني نشرها سلامة موسى في مؤلفه

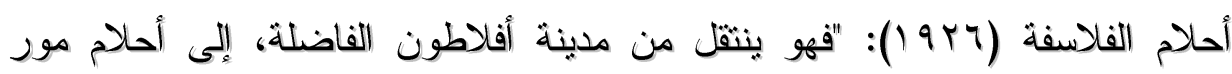

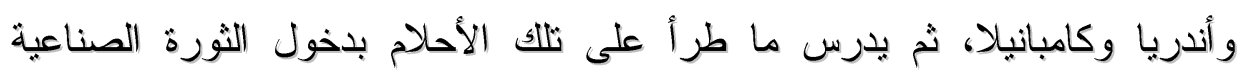

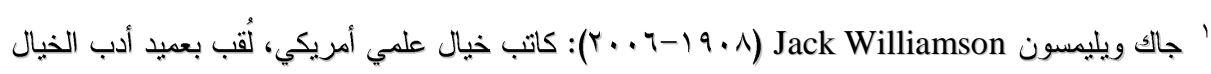
العلمي. كثب أكثر من خمسين رواية والكثير من القصص القصبرة. 
وظهور المذهب الاشتراكي، ويختم هذا كله بحلمه الخاص (خيمي) أو مصر سنة

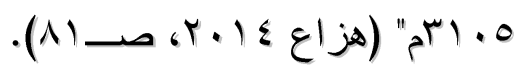

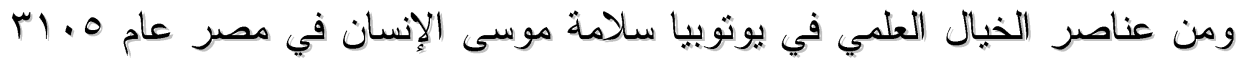

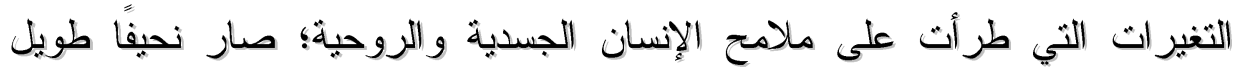
الوجه وضخم الرأس وطال عمره حتى المائة وخمسين عامًا، والفرث بين الرجل

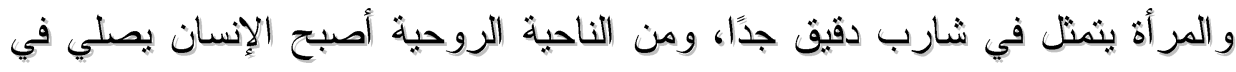
معبد ضذم وهو عبارة عن صالة تؤرخ لمر احل نطور الإنسان ثبعًا لنظرية النطور.

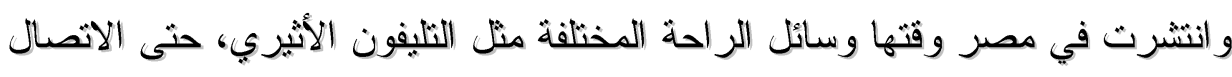

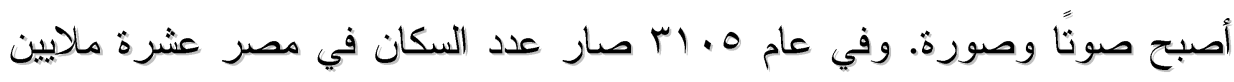

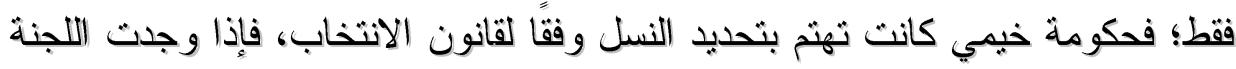

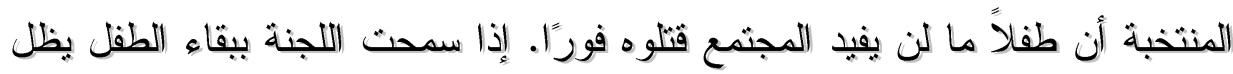

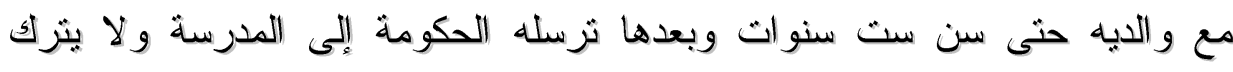

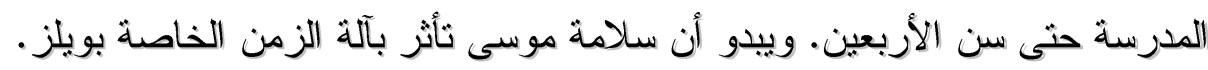

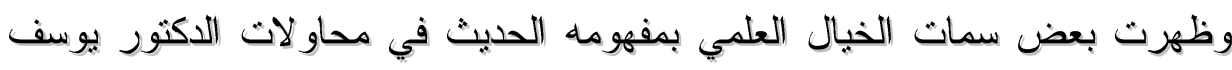

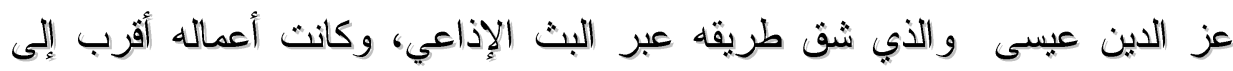

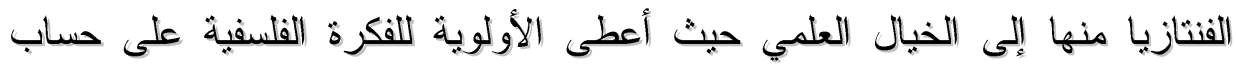

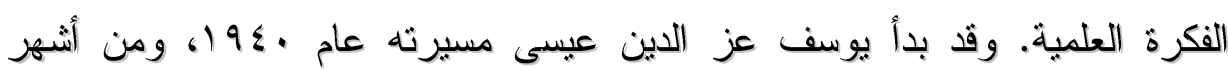

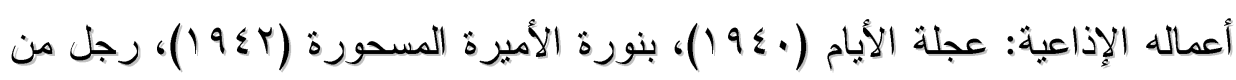

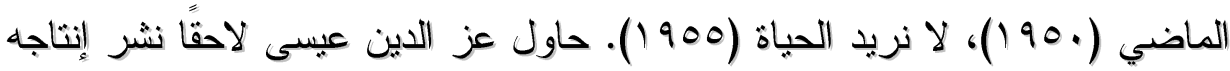
الغزير في الصحف والمجلات في السبيعنيات الثي من الصعب العثور عليها

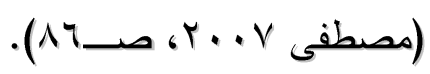

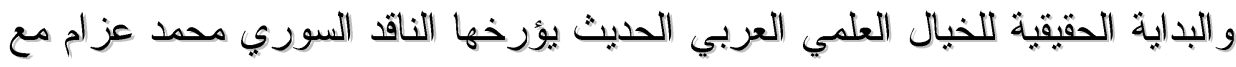
بداية ظهور أعمال شيخ الأدباء توفيق الحكيم في أدب النوع. الحكيم أول من نشرئ ئرئ

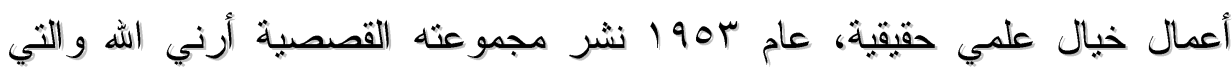




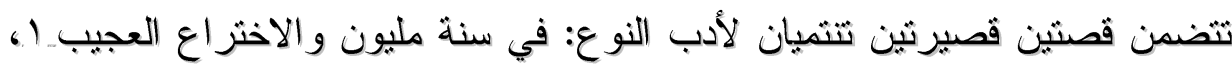

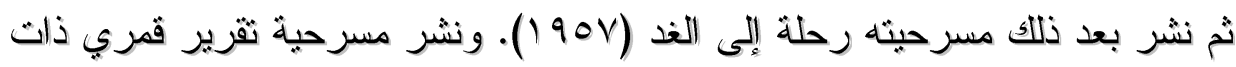

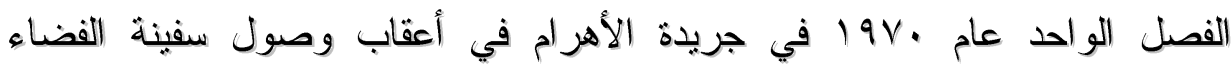
الأمريكية أبوللو 11 إلى القمر، وفي عام $19 V 1$ أنشر في جريدة الأهرام أيضًا

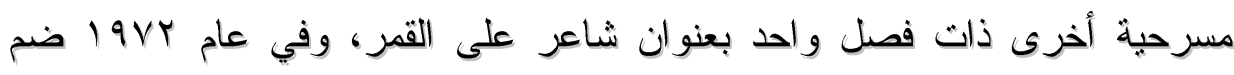
المسرحيثين في كثاب و احد مجلس العدل.

وفي الستينيات أخذت نتو الى كتابات الخيال العلمي على نحو أفضل، فظهرت مثلاً أعمال الدكتور مصطفى محمود ذات الطابع العلمي المنضبط: رواية العنكبوث ( 97 () ورواية رجل تحث الصفر (97V (1)). وفي السبعينيات بزغ نجم كاثب الخيال

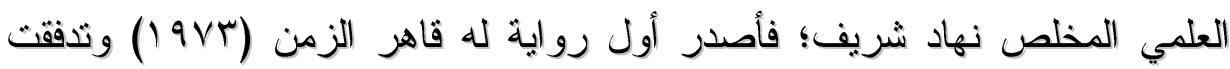

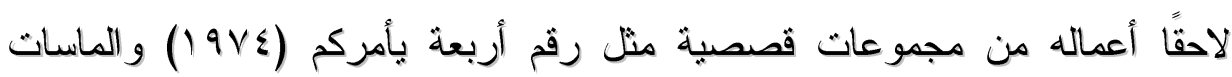
الزينونية (9V9 ())، وأثرى المسرح العربي بمسرحية أحزان السيد مكرر(.99 (1)).

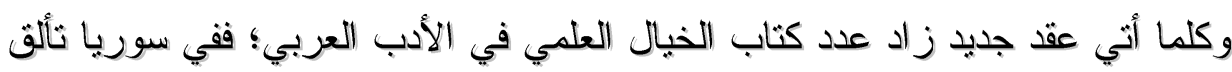

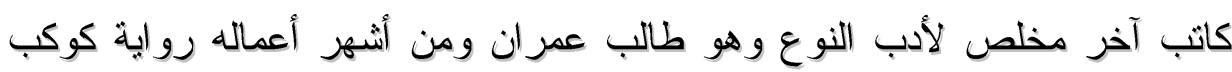

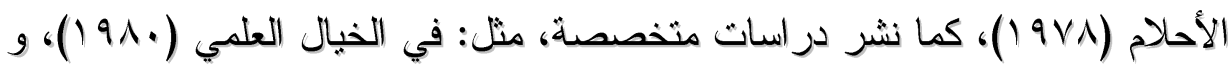

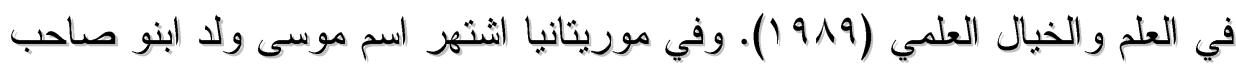
مدينة الرياح (1997)، وفي المغرب العربي أحمد عبدالسلام البقالي مبدع الطوفان الأزرث (9V7 (1))، وفي السودان جمال عبدالملك بن خلدون بروايثه العصر الأيوني

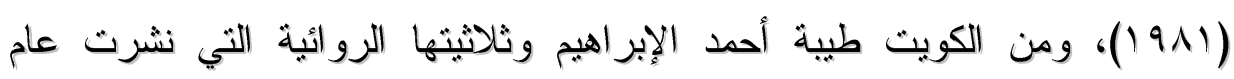

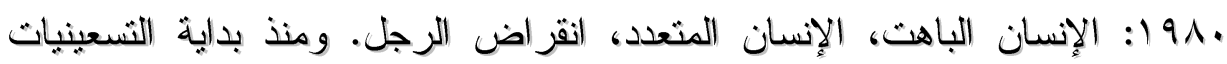

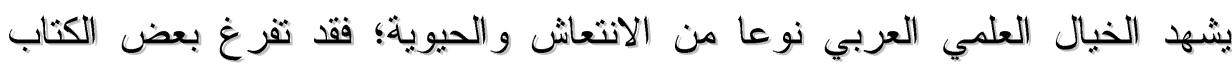

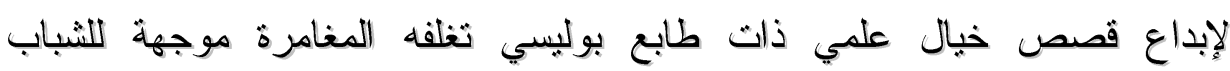

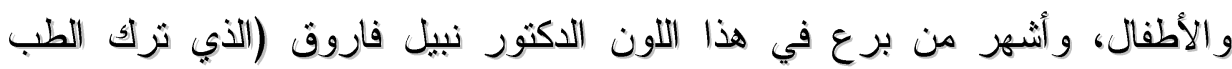

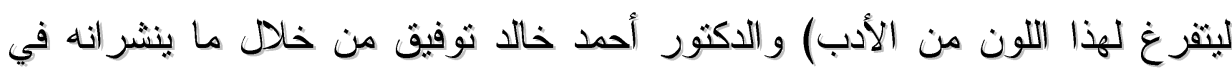

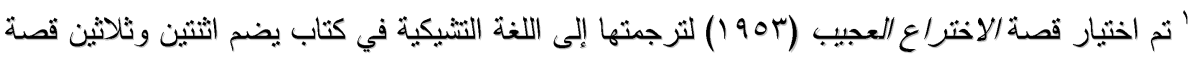

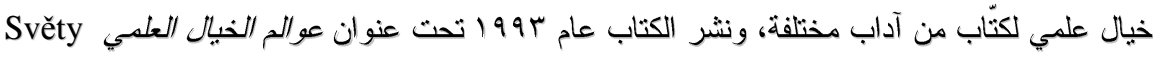
science fiction 
سلسلة ملف المستحيل، وسلسلة ما وراء الطبيعة، وسلسلة فانتازيا وغيرها. ومازال إنتاجهما مستمرًا حتى الآن. ومع الألفية الجديدة تحسن حظ أدب النوع في العالم العربي، بدأ بعض النقاد يلتفتون إلى الخيال العلمي بشكل جاد، فصدر ليوسف الثاروني دراسة نقدية بعنوان الخيال

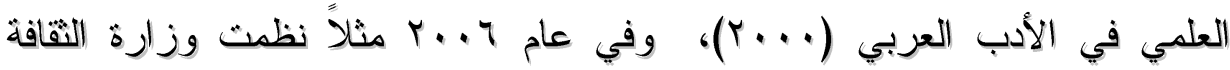

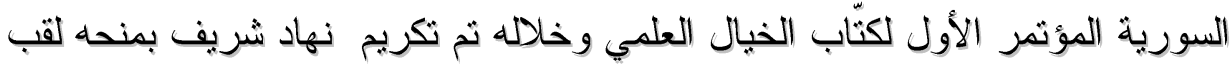
عميد كتّب الخيال العلمي العرب، كما ثم ثكريم آخرين بمنحهم شهادات ثقدير عرفانًا

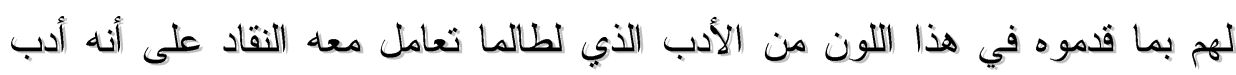

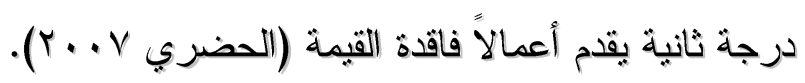

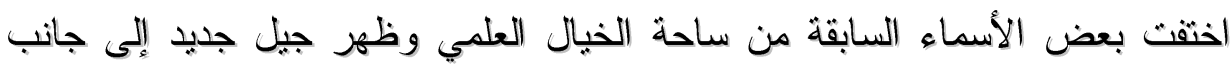
الجيل القديم أو من بقي منه. اتجه لكتابة الخيال العلمي السعودي القاهري المولد أشرف إحسان فقيه، وهو أحد القلائل المهثمين بأدب النوع في الخليج العربي، جاءت

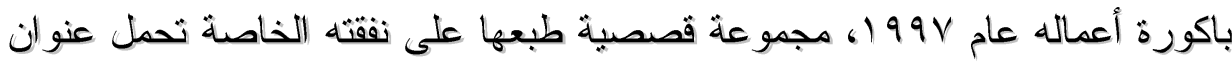

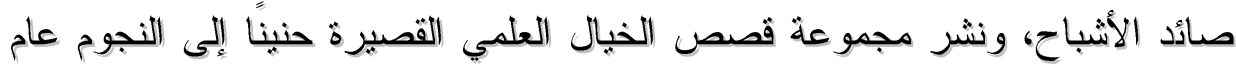

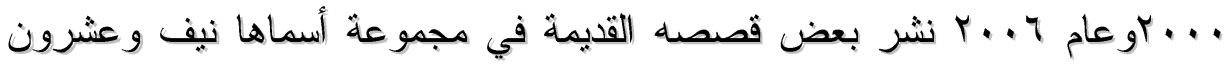

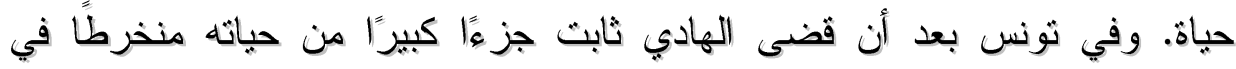

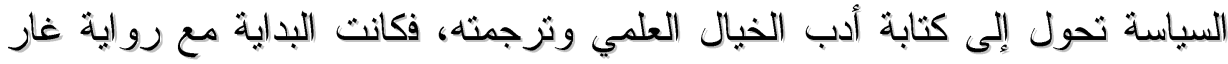

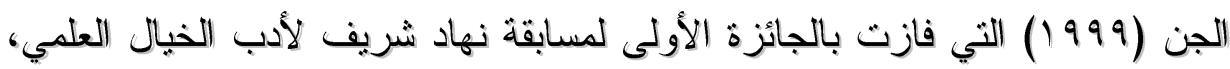

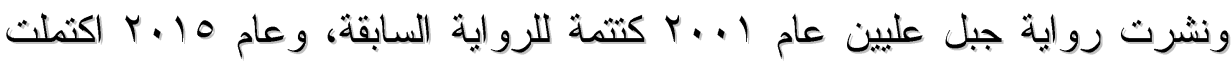

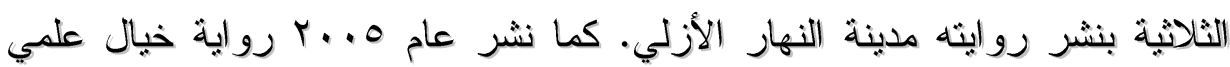

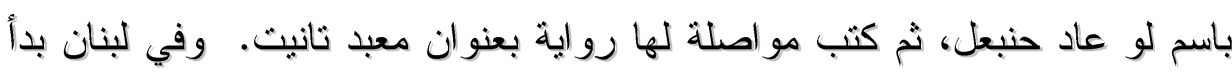

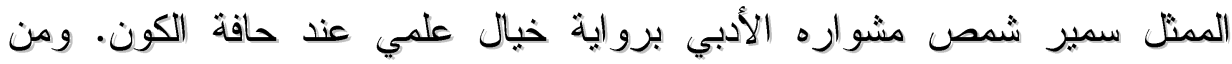

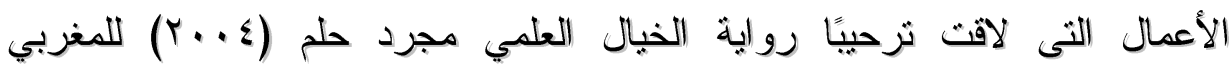

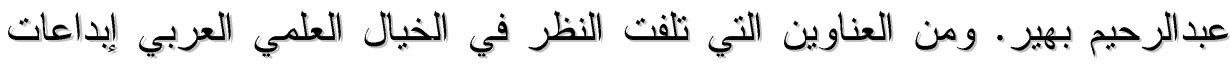
الكاتب المصري الثاب المخلص لأدب النوع أحمد محمد فريد ومن أهم أعماله: 


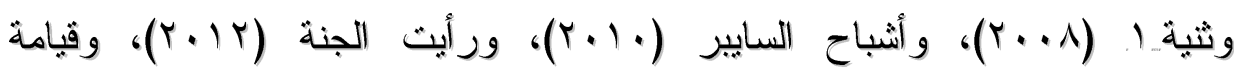
$\cdot(r \cdot 1 r)$

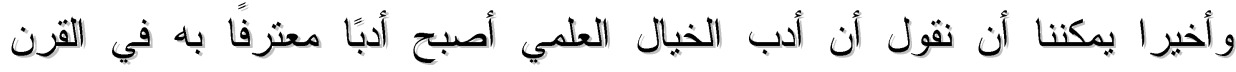

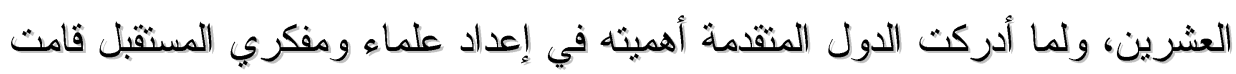

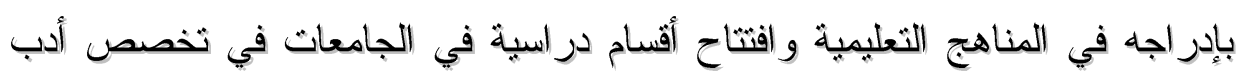

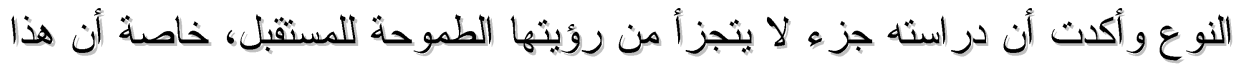

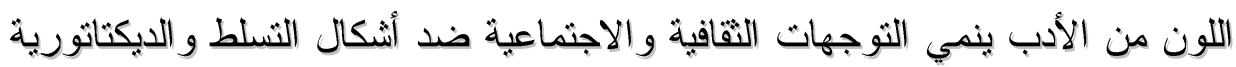
المجثمية.

\section{قائمة المراجع المستخدمة}




$$
\text { المر اجع العربية }
$$

الشاروني، يوسف: الخيال العلمي في الأدب العربي. القاهرة، الهيئة المصرية العامة

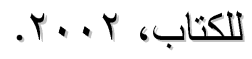

الثيخ، فتح الله: الهجرة العظمى إلى الفضاء (مسنقبل البشرية). القاهرة، الهيئة المصرية العامة للكتاب، Y I . r. توتلي، ليزا: فن كتابة الفنتازيا و الخبال العلمي. ثرجمة د. كمال الدين حسن. القاهرة،

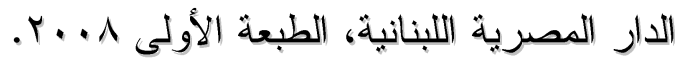
سكولز، روبرث: آفاق أدب الخبال العلمي. ثرجمة حسن حسين شكري. القاهرة، الكيئة المصرية العامة للكتاب، 1997. شريف، نهاد: الدور الحيوي لأدب الخيال العلمي في ثقافتنا العلمية. القاهرة، المكنبة

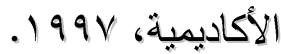
شوشة، فاروق؛ وآخرون: معجم مصطلحات الأدب (الجزء الثاني). القاهرة، مجمع

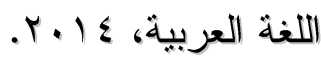
قاسم، محمود: الخيال العلمي أدب القرن العشرين. القاهرة، الهيئة المصرية العامة للكتاب، س 1999. قاسم، محمود: الخبال العلمي، مصطلحات وأسماء. القاهرة، المكثبة الأكاديمية، .$r .9$

قاسم، محمود: علم زاده الخبال (السينما والخبال العلمي). القاهرة، المكثبة الأكاديمية،

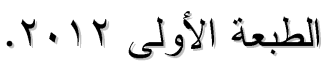
هزاع، حمادة: الخيال العلمي في الأدب المصري (نهاد شريف نموذجا). القاهرة،

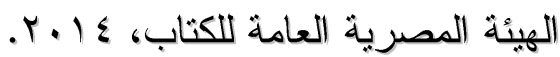
وهبة، مجدي؛ المهنس، كامل: معجم المصطلحات العربية في اللغة والأدب. بيروت، مكتبة لبنان، الطبعة الثانية، عه 19. 
Adamovič, Ivan: Slovník české literární fantastiky a science fiction (s úvodní studií fantastiky Ondřeje Neffa). R3, Praha, první vydání 1995. Genčiová, Miroslava: Vědckofantastická literatura (srovnávací žánrová studie). Albatros, Praha, první vydání 1980. Julij, Kagarlickij: Fantastika, utopie, antiutopie. Přeložil dr. Zdeněk Kubeš. Panorama, Praha, první vydání 1974.

Neff, Ondřej: encyklopedie literatury science fiction. H \& H, Praha, první vydání 1995 .

Neff, Ondřej: Všechno je jinak (Kapitoly o světové science fiction). Albatros, Praha, první vydání 1986.

Olša, Jaroslav, Jr.: Světy science fiction. Asociace fanoušků science fiction, Praha, první vydání 1993. Peterka, Josef: Teorie literatury pro učitele. MME Mercury Music \& Entertainment s.r.o., Dobřrišs, tř̌etí vydání 2007.

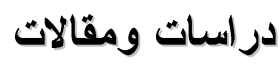

الحضري، إيهاب: أدب الخبال العلمي بنكهة عربية! الرواية حين ثتجاوز إخفاقات

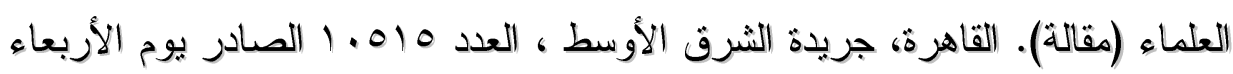
r...V

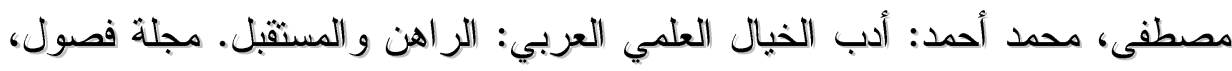

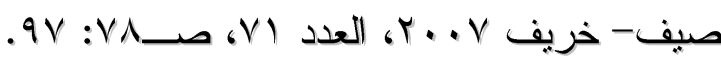

Hawking, Stephen: Uměl? inteligence mů?e znamenat zk?zu lidstva. 4.12. 2014. Dostupné z: cz/ct24/svet/1006511-hawking-umela-inteligence-muzeznamenat-zkazu-lidstva 